\title{
Effect of load, processing time and due date variation on the effectiveness of scheduling rules
}

\section{Tahar Lejmi \& Ihsan Sabuncuoglu}

To cite this article: Tahar Lejmi \& Ihsan Sabuncuoglu (2002) Effect of load, processing time and due date variation on the effectiveness of scheduling rules, International Journal of Production Research, 40:4, 945-974, DOI: 10.1080/00207540110098481

To link to this article: http://dx.doi.org/10.1080/00207540110098481

$$
\text { 曲 Published online: } 14 \text { Nov } 2010 .
$$

Submit your article to this journal




\title{
Effect of load, processing time and due date variation on the effectiveness of scheduling rules
}

\author{
TAHAR LEJMI $\dagger$ and IHSAN SABUNCUOGLU $\ddagger *$
}

In real manufacturing environments, variations in production factors (i.e. processing time, demand, due-dates) are inevitable facts. All these dynamic changes, together with random disturbances (e.g. machine breakdowns) can seriously affect the system performance. In this paper we focus on load, processing time and due date variation and analyse their impacts on a scheduling system. Specifically, we investigate the impact of variation on dispatching policies in a job shop environment via simulation. The statistical analysis of the results leads to two major conclusions: first, the relative performance of rules is not threatened much by PV (processing time variation), LV (load variation) or DDV (due date variation) - a result that can be a consolation for practitioners in the field. Secondly, the performance of the rules deteriorates, in particular at high levels of PV, LV and DDV - a result that can provide new insights into the problem and produces useful information for researchers in their continuous effort to develop better dispatching rules.

\section{Introduction}

The job-dispatching environment often requires the use of processing time estimates that are usually subject to error. An anticipated processing time is generally based on a best estimate, which is sometimes an average of the actual processing times from the previous job processing operations. In practice, the estimation of this true processing time is a difficult task due to various random factors involved in production environments (e.g. variations in machining conditions, operator, material, etc). In addition, actual processing times often differ from their estimated values due to these random factors.

For the last four decades, scheduling problems have been extensively studied in the literature. In most of the existing studies, however, randomness in processing times is not fairly incorporated in the models. In deterministic studies that constitute the majority of existing scheduling work, processing times are considered as known quantities or parameters of the problem and the best schedule is developed to optimize some performance measure (e.g. makespan, mean tardiness, mean flow time). In practice, however, the actual performance and events (start and completion times of jobs) can be significantly different from so-called predicted (or planned) performance due to various random events. For that reason, the pre-determined optimum schedules may not always yield the best results. This highlights an important point

Revision received May 2001.

$\dagger$ Department of Business Administration, Bilkent University, 06533 Bilkent, Ankara, Turkey.

t. Department of Industrial Engineering, Bilkent University, 06533 Bilkent, Ankara, Turkey.

*To whom correspondenc should be addressed. e-mail: sabun@bilkent.edu.tr 
that one should measure the deviation between the planned and realized schedules, and its impact on system performance.

Researchers have also developed stochastic scheduling models to cope with randomness in production environments. Generally speaking, stochastic problems are more difficult than their deterministic versions. In stochastic formulations, wellknown probabilistic distribution functions (e.g. normal, exponential) are assumed for processing times and jobs are scheduled using the expected quantities (e.g. mean processing times of jobs etc). The best schedule is determined so as to optimize the expected value of some performance measure (i.e. the expected sum of completion times). Even though the stochastic approach brings some realism to the scheduling systems, the optimum schedule generated by the stochastic models may not be totally different from the deterministic models. As shown by Pinedo (1995) in the single machine scheduling environment, the optimum schedule for deterministic problem may also optimize the objective of the stochastic version. Regardless of whether the schedules are generated by deterministic or stochastic models, the actual performance of the systems can be considerably different than the planned performance. Except for a few studies, this important deviation has not been thoroughly studied in the literature. We investigate this issue in this paper.

Since most scheduling problems (even the simple ones with static and deterministic assumptions) are NP-hard, researchers in the literature have frequently employed simulation to model the stochastic and dynamic nature of scheduling systems and to test the performance of various heuristics or scheduling rules. In most of these applications, processing times are sampled from random distribution functions, but these sampled quantities are used in scheduling decisions as if they are deterministic. Thus, actual (or true) processing times of jobs are assumed to be the same as expected (or anticipated) processing times. This assumption usually does not fit real situations, and there is always deviation between planned and actual performances. Hence, it is useful to examine the effects of the deviation between true and anticipated processing times on the performance of scheduling systems.

Another source of variability in practice is the workload variation that might have negative effects on the scheduling performance. The source of variability is due to the fact that the system itself experiences changes in demand over time. This can be observed in real situations where demand depends on external factors that cause its fluctuation over time. Despite the fact that variation in workload may affect system performance, scheduling problems have usually been studied in environments where uniform workload is assumed. This assumption may not fit all real situations. Therefore, it is also important to study the effect of workload variation on the effectiveness of scheduling systems.

In real job shop environments, job due dates, although fixed before jobs go on process, may undergo changes after. This can be observed in real situations where, due to some external or internal factors, manufacturers have to finish a job before or after its originally set due date. We expect that the variations that job due dates can undergo during the jobs processing, can have considerable negative impact on the performance of priority rules. Nevertheless, we are not aware of any study that has considered the phenomenon. All studies in the literature have assumed that due dates do not change once they are determined.

In this paper, we study the Load Variation (LV), Processing Time Variation (PV), and Due Date Variation (DDV) and their effects on the scheduling system. First, we test the scheduling rules for varying levels of PV. Here, PV is defined as the 
deviation between a true and an anticipated processing time. Secondly, we consider load variation and analyse the performance of the scheduling rules under four different LV schemes. Finally, we investigate the effect of due date variation on the effectiveness of priority rules. The objective is to uncover the effect of PV, LV and DDV on the performance of priority rules for the mean flow time (MF) and mean tardiness (MT) measures.

The rest of the paper is organized as follows. Section 2 presents a literature review. Section 3 gives the system considerations and experimental conditions. Section 3 also discusses modelling PV, LV and DDV. Results are presented in section 4. Finally, the paper ends with concluding remarks in section 5 .

\section{Relevant literature}

\subsection{Processing time variation}

Research on the effect of the deviation between true and anticipated processing times on priority rules performance is rare because the existing work on scheduling assumes fixed and true processing times (Smith et al. 1973). Despite the fact that some variability of processing times is assumed in scheduling problems, this variability in a research environment is due to drawing processing times from a probability distribution function. The true processing times are usually assumed to be fixed with no differences between true and anticipated processing times. Our literature survey indicates that a few works exist on this subject.

Pinedo (1982) studies the optimization problem of minimizing the completion time while taking into account the variability in job processing times from different machines in stochastic flow shops. He concludes that, to minimize the expected makespan, jobs with smaller expected processing times and larger processing time variances should be scheduled either at the beginning or at the end of the schedule. The work done by Suresh et al. (1985) supports Pinedo's conclusion. Pinedo and Weiss (1987) further develop the 'Largest Variance First' policy for minimizing both expected flowtime and expected makespan for stochastic scheduling problems. Frostig (1988) extends this study and generalizes the results of Pinedo and Weiss.

Smith et al. (1973) investigate the effects of the uncertainty of processing time estimates on scheduling rule performance by using the SPT rule and the makespan criterion. The authors observe that the uncertainty of processing time estimates affects the performance of the SPT rule in minimizing makespan. In another study, Yumin et al. (1994) examine the effect of inaccuracy of processing time estimation on the effectiveness of well-known dispatching rules (i.e. SPT, MST, EDD, FOPNR and MOPNR) for various measures such as mean flow time, mean tardiness and proportion of tardy jobs. They conclude that when the inaccuracy of processing time estimation is not large, with a standard deviation of the true and anticipated processing times being 10 , the inaccuracy does not significantly affect the performance of the scheduling rules. However, at higher levels of inaccuracy, there is obvious deterioration of the performance of priority rules. They also observe that due-date based rules are more robust than non due-date based rules.

In another study, Sabuncuoglu and Karabuk (1999) investigate the frequency of scheduling in an FMS with uncertain processing times and unreliable machines. The results indicate that both machine breakdowns and processing time variation have negative effects on the system performance. The authors also report that differences between the optimum seeking algorithms and simple scheduling rules diminish as the level of variability in the system increases. Similar observations are also made by 
Lawrence and Sewell (1997). In this study, the authors investigate the effects of stochastic processing times on scheduling methods and find that the fixed optimum sequence is outperformed by simple heuristics or dispatching rules as the variability increases. Finally, Sabuncuoglu and Comlekci (1997) consider PV in the relative comparison of flow time estimation methods. Their results indicate that the performance of the flow time estimation methods deteriorates at high PV levels.

\subsection{Load variation}

Similar to PV, most previous studies on scheduling rules ignore the possible variations of system workload over time. Researchers usually assumed uniform work load or (machine utilization) within their system models. Ramasesh (1990) who made a survey of simulation research on dynamic job scheduling, points out that most studies have been carried out at a single predetermined level of shop utilization. Carroll (1965) and Baker and Dzielinski (1960) employ an 80\% level. Eilon and Chowdhury (1976) and Weeks and Fryer (1977) use a 90\% level. Elvers (1973) uses heavily loaded shops with 97\% utilization level.

In a later study, Elvers and Taube (1983) use six different levels of shop loading to evaluate the performance of various priority rules across a shop utilization spectrum. Conway (1964) uses three utilization levels - 88.4, 90.4 and $91.9 \%$ - in his study. Hottenstein (1970) uses two levels of $72 \%$ and $94 \%$. Note that most studies set utilization levels by adjusting the arrival rate parameter of the input process.

Among the studies that considered LV, Jones (1973) points out that one might expect that changing conditions associated with increasing demands for work from a job shop will be served best by changing the scheduling rules. The same conclusion is also reached by Elvers and Taube (1983) who compare the rank-order performance of five scheduling rules against the criterion of 'percentage of on time completion'. Their results indicate that the relative performance of the rules is dependent on the shop-load level. Sabuncuoglu and Comlekci (1997) test the effect of LV on the flow time estimation method in terms of ML (mean lateness), MT and MF criteria. In this study, LV is achieved by varying randomly the arrival rate of the jobs so that the load level fluctuates within a certain margin of the average load level of the system. The results indicate that the performance of the flow time estimation method is quite robust to LV. Specifically, two LV levels are considered: $10 \%$ and $20 \%$, and at neither level has the flow time estimation method performance been affected considerably.

\subsection{Due date variation}

To the best of our knowledge there is not even a single study in the literature that examines the due date variation in the scheduling context.

\section{System considerations, simulation model and experimental conditions}

\subsection{Suggested model}

In a dynamic and stochastic manufacturing environment, testing scheduling rules under different experimental conditions becomes a more complex task than in the static case. It follows from the fact that one should be very careful on the model choice. The generality aspect of such a model must be kept at a maximum in order to get potential benefits from the experiments. Our model is similar to the one used by Vepsalainen and Morton (1987). It is a re-entrant dynamic job shop model with: 
- Ten machines are continuously available.

- Continuous arrival of jobs having a Poisson distribution.

- Number of operations assigned to each job arrived is random having a uniform distribution $\mathrm{U}[1,10]$.

- Each operation is equally likely to be performed on ten machines, where processing times are random having a uniform distribution $\mathrm{U}[1,30]$.

The assumptions of this model are given in the study by Vepsalainen and Morton (1987).

\subsection{System load (or machine and shop utilization)}

The combined effects of job arrival distribution, job routing and processing times determine system load (or the machine utilization). From the standpoint of job-shop simulation, machine utilization is important because it affects queue lengths. If the average queue length is too small, the scheduling rules used in the model may not be forced to make discriminating job selections; when this situation occurs, an evaluation of rule effectiveness is difficult or impossible. Adverse effects also result from machine utilization when it is too high. If utilization is near $100 \%$, transient conditions may extend over a long time period. Machine utilization commonly found in the literature ranges from $60 \%$ to $95 \%$. This range of utilization permits scheduling rules to select a job from several in the queue but does not lead to very long queues. In our study, when analysing the effects of PV and DDV, we consider two levels of machine utilizations: $60 \%$ (low) and $85 \%$ (high). In the LV case, however, we start with an initial $72.5 \%$ level (which corresponds to the medium utilization level) and change it according to the LV scheme under consideration by adjusting the arrival rate.

\subsection{Due date tightness and assignment rule}

Due date performances of the rules are affected by due date tightness. In general, tighter due dates tend to produce larger values of MT (mean tardiness) and PT (proportion of tardy jobs), if other conditions remain unchanged (Carroll 1965). Beyond that there is also evidence that the relative performance of priority rules is also affected by due date tightness, at least for PT and for MT. This suggests the existence of so-called cross-over points, with one rule performing best for tighter due dates and another performing best for looser due dates. In this study, we use the TWK approach in assigning the due dates. The reason is that the TWK method is found to be the most efficient rule to reduce the cross-over effect (Baker 1984). According to TWK, job due dates are defined as follows:

$$
D_{j}=R_{j}+A_{j},
$$

where, $A_{j}=k \times P_{j}$ represents the original flow allowance, $k$ is the due date tightness value and $R_{j}$ denotes the arrival time of job $j$.

Baker (1984) suggests that $10 \%$ and $40 \%$ PT values represent loose and relatively tight due dates respectively. These PT values are used as the reference values to apply due date tightness to the simulation experiments in almost all every study, except that we have lately performed some experiments at extremely tight due dates for the symmetric criterion, Mean Absolute Deviation (MAD). In order to set tight due 
dates or loose due dates, the parameter $k$ should be adjusted so that we achieve the desired PT values mentioned previously (i.e. $10 \%$ and $40 \%$ values). In this study, we use separate pilot runs to set the values of $k$, with respect to FCFS (benchmark rule) for different machine utilization levels. Note that the same value of $k$ is used for all tested priority rules under the same utilization level.

\subsection{Scheduling rules}

According to previous studies, SPT (Shortest Processing Time) and MOD (Modified Operation Due date) rules are considered the most effective rules for completion time and tardiness based criteria. Note that SPT and MOD are described as local rules. We define local priority rules as those that require information only about those jobs that are waiting at a machine, while global rules require additional information about jobs or machine states or other machines. STPT (Shortest Total Processing Time) and the MDD (Modified job Due Date) rules can be considered as the global rules in this context. In this study we use these four rules. We believe that using local and global rules makes the results of the study more general and reliable. To seek further generality, we use two other local/global pairs of rules: ODD (Operation Due Date) and EDD (Earliest Due Date) rules, which are again simple but effective rules. FCFS (First Come First Served) and FAFS (First Arrived First Served) rules are included as benchmark rules.

\subsection{Performance criteria}

In this study, we employ two scheduling performance measures: the mean flow time (MF) and the mean tardiness (MT). The former criterion represents a speed of response in the manufacturing environment (lead-time) and is a good indicator of the production rate (or throughput). The latter criterion is a due-date based measure that measures the average level of customer satisfaction in terms of delivery performance. These two are the most frequently used scheduling criteria in the literature.

\subsection{Modelling $P V$}

In order to model the processing time variation, we induce some perturbation in the processing times using the approach suggested by Sabuncuoglu and Comlekci (1997). That is, best estimates are drawn from the uniform distribution but only some percentages (plus or minus) of the sampled quantities are used as the actual processing times. The details are as follows:

$$
p_{i j}^{\prime}=(1+\mathrm{PV} \% \times \mathrm{UNIF}[-1,1]) \times p_{i j},
$$

where

$$
\begin{aligned}
p_{i j} & \text { estimated processing time value drawn from the uniform distribution, } \\
p_{i j}^{\prime} & \text { true (actual) processing value, deviated from its estimated value, } \\
\text { PV } \% & \text { PV level percentage. }
\end{aligned}
$$

Seeking generality, we test with $0 \%, 20 \%, 40 \%$ and $60 \% \mathrm{PV} \%$ values. A point to note is that scheduling rules use estimated processing times to assign job priorities during the dispatching process, but when processing on machines occur, actual or true processing times are used to delay the operations. 


\subsection{Modelling $L V$}

In real job-shop systems, due to some external factors, demand undergoes variation over time. This, in turn, causes the system workload to experience similar variation. In general, workload changes can occur in different ways. In our study, we consider four different schemes that would reflect most possible workload variation behaviours. The first scheme represents a random change of workload over time. The second one is inspired from real situations where workload is seasonal. The last two alternatives consider the cases where workload is either continuously increasing or decreasing respectively. All these four load schemes are established by varying the arrival rate of the jobs to the system, as shown in the following four schemes.

\section{Notation}

$\lambda$ current arrival rate for current $k$ jobs arrived,

$\lambda^{\prime}$ new arrival rate for next $k$ jobs,

$\lambda_{0}$ initial arrival rate, assigned at the beginning of each replication,

$\lambda_{\min }$ lower bound for arrival rate,

$\lambda_{\max }$ upper bound for arrival rate,

$\Re$ maximum increases or decrease range size. $\Re=\lambda_{\max }-\lambda_{\min }$,

LV\% a percentage value, a parameter that controls how much $\lambda$ can maximally vary,

$\tau$ an increase/decrease index value, where

- at the beginning of each replication, $\tau_{0}=$ DISC. UNIF $[-1,1]$

- after that time, $\tau$ is updated as follows:

$$
\begin{aligned}
& \tau= 1 \text { if } \lambda^{\prime}<\lambda_{\min } \\
&-1 \text { if } \lambda^{\prime}>\lambda_{\max }, \\
& n \quad \text { job batch size, } \\
& N \quad \text { total job number of jobs arriving per replication. }
\end{aligned}
$$

\section{Scheme 1: (Random LV)}

As illustrated in figure 1(a), the system workload level changes randomly over time. This is usually due to random demand (i.e. demand has no particular change pattern over time). In order to incorporate random LV to our model, whenever $n$ jobs enter the system, the arrival rate $\lambda$ is updated as follows:

$$
\lambda^{\prime}=\lambda_{0}+\mathrm{UNIF}(-\mathrm{LV} \% \times \Re / 2, \mathrm{LV} \% \times \Re / 2) .
$$

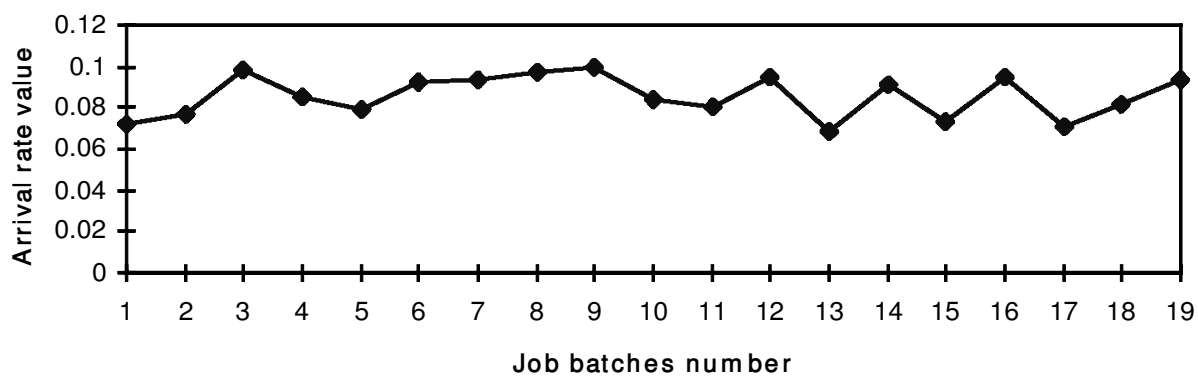

Figure 1. (a) Illustration of random arrival rate. 


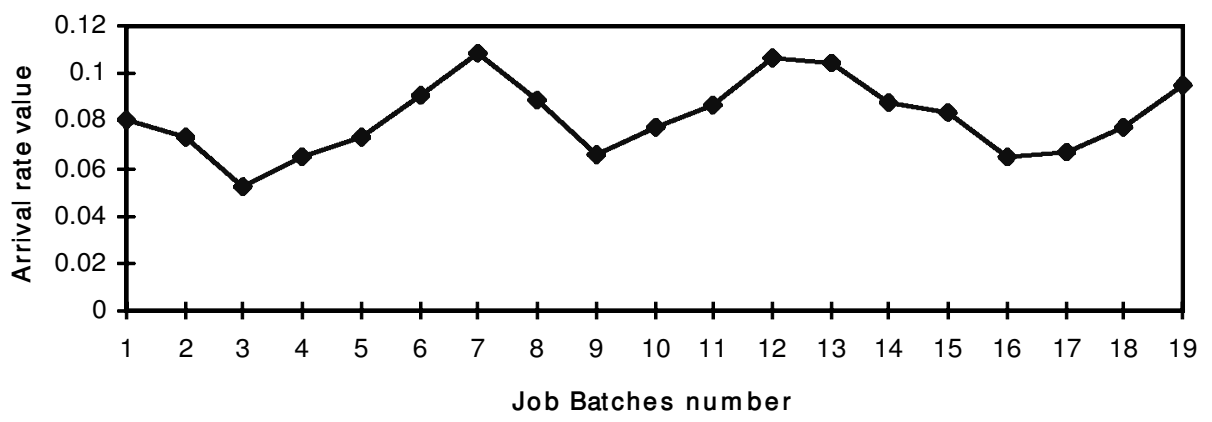

Figure 1. (b) Illustration of seasonal arrival rate.

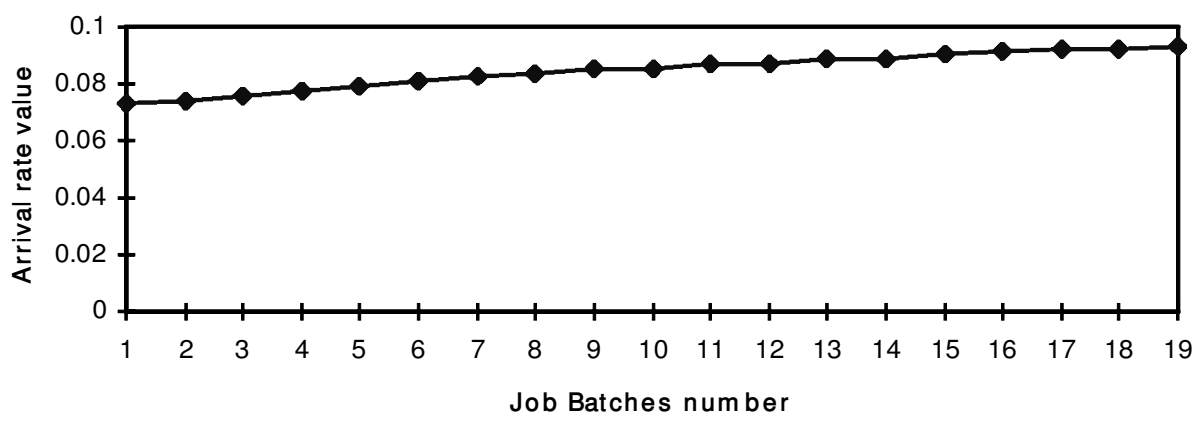

Figure 1. (c) Illustration of increasing arrival rate.

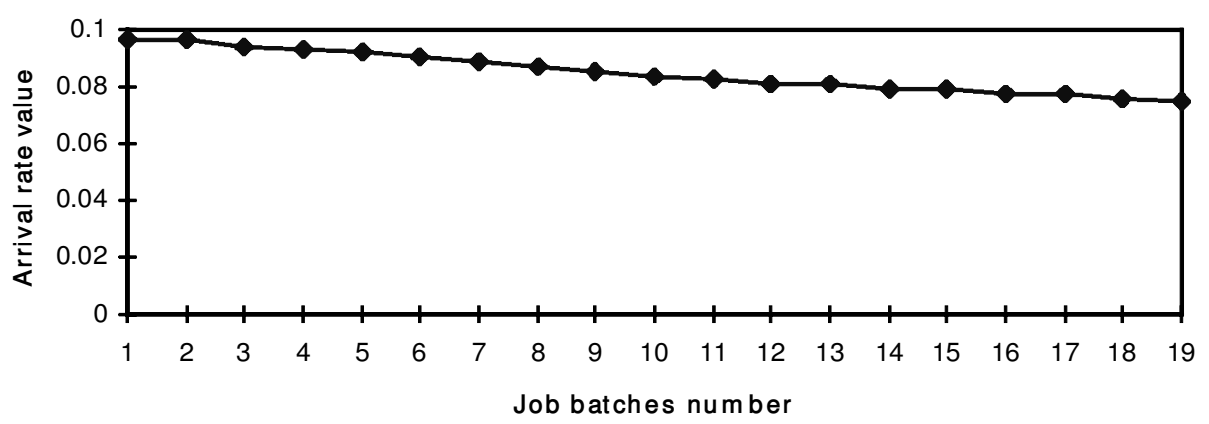

Figure 1. (d) Illustration of decreasing arrival rate.

\section{Scheme 2: (Seasonal LV)}

According to this LV scheme, demand is seasonal; that is, demand experiences a continuous increase/decrease followed by a continuous decrease/increase in repeated periodic cycles (see figure $1(b)$ ). In order to incorporate seasonal LV to the model, we cause the arrival rate $\lambda$ to change in such a way that it increases constantly until it reaches an upper bound level, then decreases again in a similar way until it reaches a lower bound level. This decrease/increase behaviour continues as far as jobs are entering the system. This approach is applied as follows. 
At the beginning of each replication: initialize $\lambda$ to $\lambda_{0}$.

After each $n$ jobs arrived, $\lambda$ is updated as follows:

$$
\lambda^{\prime}=\lambda+\tau \times \mathrm{UNIF}(0, \mathrm{LV} \% \times \Re)
$$

\section{Scheme 3: (Increasing workload)}

In this case, the arrival rate undergoes a positive variation after each $n$ jobs arrival (see figure $1(c)$ ). In the model, it is updated as follows:

Initially, $\lambda_{0}=\lambda_{\min }$.

After then,

$$
\lambda^{\prime}=\lambda+\operatorname{UNIF}(0,(3 / 2 \times n \times \Re) / N) \text {. }
$$

\section{Scheme 4: (Decreasing workload)}

In the final case, we deal with real situations where demand is continuously decreasing (figure $1(d)$ ). The arrival rate in this case undergoes a negative variation (i.e. decrease) after each $\mathrm{n}$ jobs arrival and it is updated as follows:

Initially, $\lambda_{0}=\lambda_{\max }$.

After then,

$$
\left.\lambda^{\prime}=\lambda-\operatorname{UNIF}(0,(3 / 2 \times \mathrm{n} \times \Re) / N)\right) \text {. }
$$

\section{Numerical values $P V$}

In the PV study, $60 \%$ and $85 \%$ are used as low and high machine utilizations. These levels correspond to arrival rate values of $1 / 14.5$ and $1 / 10.3$, respectively. Accordingly, the arrival rate bounds are determined as follows:

$$
\begin{array}{ll}
\lambda_{\min } & 1 / 14.5, \\
\lambda_{\max } & 1 / 10.3,
\end{array}
$$

Accordingly:

$$
\Re=\lambda_{\max }-\lambda_{\min }=1 / 10.3-1 / 14.5=0.028 .
$$

Seeking generality, the four approaches will be applied initially with a medium machine utilization environment: $72.5 \%$ level. The pilot runs indicate that the corresponding arrival rate is $1 / 12$. In the first two LV schemes, at the beginning of every replication, the arrival rate is initialized to $\lambda_{0}=1 / 12$. Recall that we use the batch means approach in the experiments. Every batch consists of $N=900$ jobs. For convenience, we assign $n=45$, which induces about 20 changes in the arrival rate in each replication. $\mathrm{LV} \%$, the parameter that controls how much $\lambda$ can maximally vary will take two different values, $40 \%$ and $80 \%$. In fact, when we increase the $\mathrm{LV} \%$ value, we increase at the same time the LV rate.

\subsection{Modelling $D D V$}

As mentioned in section 3.3, the TWK method is used to set due dates in this study. In modelling this situation, each job is given a certain flow allowance once it enters the system. As the job moves from one machine to another, with a certain probability $p$, it will undergo a change in its actual due date. Practically, in real job shops, a job will have its due date either postponed or made more urgent. This will depend on two major factors or players, the first is the manufacturer side and the 
second is the customer side. Therefore, two scenarios can occur: first, if the job is expected to be late, or technically speaking, the job's slack time is non-positive, than the manufacturer may be obliged to ask the customer to agree on postponing the job's due date by a sufficient amount of time (at least equal to its expected remaining manufacturing time). The next scenario occurs when the job is not to be late. In this case, the job's slack time is positive. Consequently, the job due date can be either postponed or made more urgent. This can occur in real situations where the customer needs the job to be finished either less or more urgently. Consequently, the manufacturer may agree to change the job due date, within some limitations that are set according to the actual status of the job. These two scenarios are defined as follows.

After finishing a certain operation of a job, with a small probability $p$.

(1) If its slack time at time $t, S_{j}\left(=d_{j}-t-P_{j}\right.$, where $P_{j}$ is the remaining operation time) is positive, then the actual due date undergoes either a positive or negative change, which equals $D V \times S_{j}$, where $D V$ is the due date variation coefficient (which would range from 0.2 until 0.8 ).

(2) Otherwise, the job due date is postponed by being adding $(1+0.5 \times D V) \times\left|S_{j}\right|$ as a sufficient time to finish the job.

A point worth noting is that the experimental factors that would be controlled during the study are:

- The probability of undergoing due date change $p$ : a small value 0.05 will initially be used and then this will be increased to 0.10 to see the major effects of increasing the due date change rate.

- The due date variation coefficient DV: this will range from $20 \%, 40 \%, 60 \%$ and $80 \%$.

Of course, this approach could be more elaborate and improved, yet it will satisfy the goal of this study.

\subsubsection{Due date variation analysis in terms of Mean Tardiness.}

The expression for MT performance measure is as follows:

$$
M T=\sum_{i=1}^{n} \frac{T_{j}}{n},
$$

where,

$T_{j} \max \left(C_{j}-D_{j}, 0\right)$, job $j$ tardiness,

$C_{j}$ completion time of job $j$,

$D_{j} \quad$ due date of job $j$.

Once due date variation is included in the analysis, the MT performance of priority rules can change in terms of two main components. The first is the completion time of each job, $C_{j}$. Since the due dates of some jobs change, their relative priority might change and, consequently, the completion times of jobs change. This effect, due to changes, in $C_{j}$ s is called the Type-I effect. The second component is the due date $D_{j}$. Recall that the tardiness is a function of due dates. Thus, as the due dates of some jobs change, their tardiness values, in turn, change. This effect is called 
the Type-II effect. The due date variation effect due to these two components determines the Overall effect on the MT performance of the priority rules.

In fact, it is important to differentiate between these three types of effects. The Type-I effect measures the new performance of the rule when it considers new due dates while assigning job priorities during the dispatching process. That leads to new completion times of the jobs in the process. However, the performance is measured in terms of the original due dates. In other words, the Type-I effect can be viewed as the net effect of due date variation on the dispatching policy performance. Note that non due-date based rules are insensitive to the Type-I effect as they do not consider any due date information.

On the other hand, the Type-II effect gives the new performance of the rules when they disregard any change in job due dates during the dispatching process. However, their MT performance is measured in terms of the final due dates. A point to note is that non due-date based rules are only sensitive to this type of effect, while due-date based rules are affected by both effects. The overall effect is the combination of these two effects and reflects the global effect of due-date variation on the rule's performance in terms of both changes in due date values and the dispatching policy performance.

According to these three due date variation effects, table 1 represents the corresponding tardiness $\left(T_{j}\right)$ equations upon which the three effects could be measured. We also present the rules sensitive to such due date variation effects. A graphical illustration of these type of effects is shown in figure 2.

In fact, the Type II effect simply measures the due date variation scheme that we adopt in terms of due date value changes, which is not of much concern to the scope of the study. Consequently, only Type-I and Overall effects will be measured throughout the simulation experiments.

\subsection{Output data analysis}

The simulation model is developed using the SIMAN language (Pegden et al. 1995). The model is verified and validated with reference to the hypothetical model suggested previously. The common random number variance reduction technique $(\mathrm{CRN})$ is implemented to compare the rules under identical conditions and to reduce the experimental error. Initially, some pilot runs are taken to find suitable values for the arrival rate to set the desired utilization levels. Two values are found for the

\begin{tabular}{llll}
\hline Effect type & Tj's Equation & Rules affected & Rules not affected \\
\hline Type I & $T_{j}=\operatorname{Max}\left(C_{j}^{n}-D_{j}^{o}, 0\right)$ & EDD, ODD, MOD, & SPT, STPT, FCFS, \\
& & MDD & FAFS \\
Type II & $T_{j}=\operatorname{Max}\left(C_{j}^{0}-D_{j}^{n}, 0\right)$ & All rules & None \\
Overall & $T_{j}=\operatorname{Max}\left(C_{j}^{n}-D_{j}^{n}, 0\right)$ & All rules & None \\
\hline
\end{tabular}

where,

$C_{j}^{0}$ : Original (No due date variation) completion time of job $j$

$D_{j}^{o}$ : Original due date of job $j$

$C_{j}^{n}$ : New completion time of job $j$

$D_{j}^{n}$ : Final due date of job $j$

Table 1. Corresponding $T_{j}$ equations to due date variation effect types. 


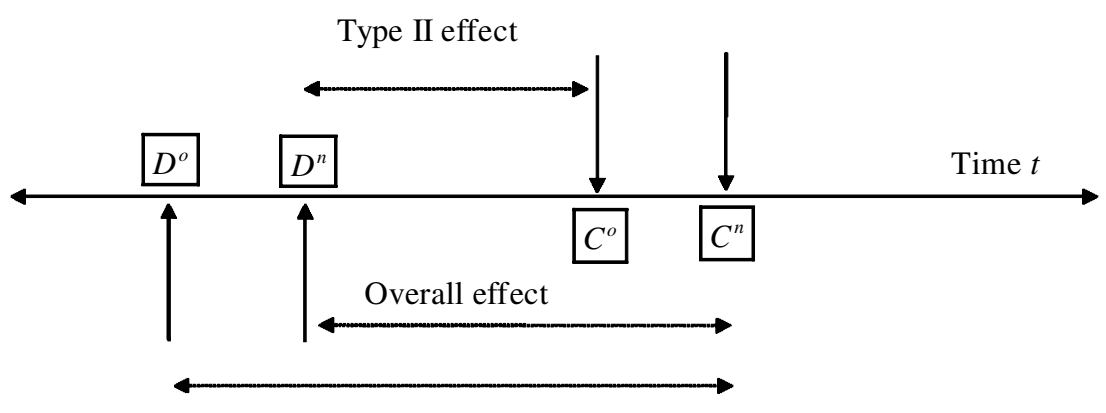

Type I effect

Figure 2. Illustration of Type-I, Type-II and overall DV effects.

\begin{tabular}{lll}
\hline & Tight due dates & Loose due dates \\
\hline High machine utilization $(85 \%)$ & $k=4.5$ & $k=7$ \\
Low machine utilization $(60 \%)$ & $k=2$ & $k=3$ \\
\hline
\end{tabular}

Table 2. Due date tightness parameter $k$ values for PV.

arrival rate: 10.3 and 14.5 , corresponding to $85 \%$ and $60 \%$ utilization levels, respectively. Furthermore, several other runs are also taken to estimate the warm-up period using the Welch approach discussed in Law and Kelton (1991). As a result, 300 job completions are deleted at the beginning of each run to reduce the effect of initial bias. In order not to lose too much computer time, the batch means approach is used, ten batches of size 900 are analysed for each experiment run. For PV and DDV, pilot runs are also taken to set the parameter $k$ for each machine utilization level, as shown in table 2. In the LV case, the same population of rules is tested in the experiments at the medium $72.5 \%$ utilization level for tight and loose due dates. According to pilot runs, the due date tightness factor $k$ is set to 2.6 and 4.5 , respectively.

\section{Analysis of the simulation results}

\subsection{Results of processing time variation}

Two classes of scheduling rules are tested in this study. The first class consists of non due-date based rules: SPT, STPT, FAFS and FCFS. The second class includes due-date based rules: EDD, ODD, MOD and MDD. All rules are tested under three levels of PV: $20 \%, 40 \%$ and $60 \%$ and two performance measures, MF and MT. To seek generality, two system load levels $(85 \%$ and $60 \%)$ as well as two due date tightness (tight and loose) levels are considered. The results of the simulation runs are presented in tables 3 and 4 . The paired $t$-tests are applied to compare the best rule with the next best rule at a significance level of $5 \%$. The symbol $(*)$ indicates when the difference between the rules is significant. In addition, the paired $t$-tests are also used to compare the performances of each rule as the processing time variation level $(\mathrm{PV} \%)$ increases. The symbol $(* *)$ indicates that the difference between original performance (no PV) and actual performance (with PV) is significant. Figures 3 


\begin{tabular}{|c|c|c|c|c|}
\hline \multirow[b]{4}{*}{ SPT } & \multicolumn{4}{|c|}{ Processing time variation Level \% } \\
\hline & $0 \%$ & $20 \%$ & $40 \%$ & $60 \%$ \\
\hline & \multicolumn{4}{|c|}{ High utilization $(85 \%) /$ tight due-dates $(k=4.5)$} \\
\hline & $261.52(*)$ & $262.32(*)$ & $268.86(*)(* *)$ & $281.94(*)(* *)$ \\
\hline STPT & 308.78 & 311.73 & $325.40(* *)$ & $323.17(* *)$ \\
\hline FCFS & 342.02 & 339.90 & $355.74(* *)$ & $373.47(* *)$ \\
\hline FAFS & 335.11 & 337.22 & $342.05(* *)$ & $366.85(* *)$ \\
\hline EDD & 318.31 & 318.71 & $324.08(* *)$ & $340.75(* *)$ \\
\hline ODD & 310.95 & 312.54 & $326.86(* *)$ & $336.78(* *)$ \\
\hline MOD & 300.47 & 301.38 & $312.11(* *)$ & $321.36(* *)$ \\
\hline \multirow[t]{2}{*}{ MDD } & 316.33 & 318.83 & $328.32(* *)$ & $338.34(* *)$ \\
\hline & \multicolumn{4}{|c|}{ High utilization $(85 \%) /$ loose due-dates $(k=7)$} \\
\hline SPT & $261.52(*)$ & 262.32(*) & $268.86(*)(* *)$ & $281.94(*)(* *)$ \\
\hline STPT & 308.78 & 311.73 & $325.40(* *)$ & $323.17(* *)$ \\
\hline FCFS & 342.02 & 339.90 & $355.74(* *)$ & $373.47(* *)$ \\
\hline FAFS & 335.11 & 337.22 & $342.05(* *)$ & $366.85(* *)$ \\
\hline EDD & 314.21 & 317.21 & $325.80(* *)$ & $351.09(* *)$ \\
\hline ODD & 315.77 & 318.23 & $331.92(* *)$ & $335.01(* *)$ \\
\hline MOD & 314.68 & 315.99 & $324.47(* *)$ & $342.07(* *)$ \\
\hline \multirow[t]{2}{*}{ MDD } & 314.81 & 315.29 & $326.20(* *)$ & $342.26(* *)$ \\
\hline & \multicolumn{4}{|c|}{ Low utilization $(60 \%) /$ tight due-dates $(k=2)$} \\
\hline SPT & $149.33(*)$ & $150.39(*)$ & $152.27(*)$ & $156.76(*)(* *)$ \\
\hline STPT & 159.55 & 160.84 & $164.20(* *)$ & $167.50(* *)$ \\
\hline FCFS & 164.87 & 166.05 & $169.59(* *)$ & $174.44(* *)$ \\
\hline FAFS & 163.32 & 165.05 & 167.16 & $172.74(* *)$ \\
\hline EDD & 159.37 & 160.89 & 163.28 & $167.99(* *)$ \\
\hline ODD & 157.59 & 159.43 & 161.96 & $166.45(* *)$ \\
\hline MOD & 154.3 & 154.28 & 157.77 & $160.30(* *)$ \\
\hline \multirow[t]{2}{*}{ MDD } & 158.29 & 159.89 & 161.23 & $166.88(* *)$ \\
\hline & \multicolumn{4}{|c|}{ Low utilization $(60 \%) /$ loose due-dates $(k=3)$} \\
\hline SPT & $149.33(*)$ & $150.39(*)$ & $152.27(*)(* *)$ & $156.76(*)(* *)$ \\
\hline STPT & 159.55 & 160.84 & $164.20(* *)$ & $167.50(* *)$ \\
\hline FCFS & 164.87 & 166.05 & $169.59(* *)$ & $174.44(* *)$ \\
\hline FAFS & 163.32 & 165.05 & 167.16 & $172.74(* *)$ \\
\hline EDD & 159.61 & 159.54 & 162.25 & $167.07(* *)$ \\
\hline ODD & 158.92 & 159.23 & 163.48 & $166.69(* *)$ \\
\hline MOD & 158.82 & 160.39 & 162.53 & $166.13(* *)$ \\
\hline MDD & 159.45 & 159.52 & 161.95 & $167.46(* *)$ \\
\hline
\end{tabular}

(*) Statistically significant at 5\% for tables 3 through 16

(**) Statistically significant deterioration at $5 \%$ for Tables 3 through 16

Table 3. Processing time variation simulation results for MF.

and 4 are also provided to depict the behaviour of the system performance as a function of PV. From the analysis of the results, the following observations are made.

In all experimental conditions, SPT yields the best MF values. The second best performance is displayed by MOD and STPT. The latter rule performs especially well at the high utilization/loose due-dates condition. These two rules are followed by ODD, MDD and EDD. All these rules outperform the benchmark rules FCFS 


\begin{tabular}{|c|c|c|c|c|}
\hline \multirow[b]{4}{*}{ SPT } & \multicolumn{4}{|c|}{ Processing time variation Level \% } \\
\hline & $0 \%$ & $20 \%$ & $40 \%$ & $60 \%$ \\
\hline & \multicolumn{4}{|c|}{ High utilization $(85 \%) /$ tight due-dates $(k=4.5)$} \\
\hline & 37.81 & 37.65 & $40.52(* *)$ & $45.66(* *)$ \\
\hline STPT & 73.03 & 74.41 & $84.89(* *)$ & $81.12(* *)$ \\
\hline FCFS & 45.55 & 45.17 & $50.61(* *)$ & $62.23(* *)$ \\
\hline FAFS & 48.55 & 48.11 & $50.46(* *)$ & $63.54(* *)$ \\
\hline EDD & 20.77 & 19.64 & 22.18 & $30.07(* *)$ \\
\hline ODD & 17.34 & 17.30 & $21.29(* *)$ & $26.09(* *)$ \\
\hline MOD & $13.13(*)$ & $12.76(*)$ & $16.57(*)(* *)$ & $18.42(*)(* *)$ \\
\hline \multirow[t]{2}{*}{ MDD } & 19.05 & 19.62 & $23.92(* *)$ & $29.06(* *)$ \\
\hline & \multicolumn{4}{|c|}{ High utilization $(85 \%) /$ loose due-dates $(k=7)$} \\
\hline SPT & 20.3 & 19.60 & 21.62 & $23.98(* *)$ \\
\hline STPT & 40.14 & 41.01 & $49.14(* *)$ & $45.45(* *)$ \\
\hline FCFS & 11.07 & 11.20 & 12.48 & $16.21(* *)$ \\
\hline FAFS & 19.92 & 19.57 & 20.38 & $26.30(* *)$ \\
\hline EDD & $0.25(*)$ & 0.28 & $0.57(* *)$ & $1.52(* *)$ \\
\hline ODD & 0.54 & 0.46 & $0.84(* *)$ & $1.00(*)(* *)$ \\
\hline MOD & 0.51 & 0.40 & $0.60(* *)$ & $1.17(* *)$ \\
\hline \multirow[t]{2}{*}{ MDD } & 0.33 & 0.27 & $0.56(* *)$ & $1.19(* *)$ \\
\hline & \multicolumn{4}{|c|}{ Low utilization $(60 \%)$ /tight due-dates $(k=2)$} \\
\hline SPT & 12.58 & 13.09 & 14.52 & $17.72(* *)$ \\
\hline STPT & 19.43 & 20.27 & $23.04(* *)$ & $25.67(* *)$ \\
\hline FCFS & 19.92 & 20.65 & $23.28(* *)$ & $26.90(* *)$ \\
\hline FAFS & 21.06 & 22.00 & 23.75 & $27.22(* *)$ \\
\hline EDD & 14.8 & 15.65 & $17.29(* *)$ & $20.85(* *)$ \\
\hline ODD & 11.62 & 12.65 & $14.52(* *)$ & $17.28(* *)$ \\
\hline MOD & $9.74(*)$ & $9.90(*)$ & $12.33(*)$ & 13.78(*) \\
\hline \multirow[t]{2}{*}{ MDD } & 14.23 & 15.13 & $16.69(* *)$ & $20.10(* *)$ \\
\hline & \multicolumn{4}{|c|}{ Low utilization $(60 \%) /$ loose due-dates $(k=3)$} \\
\hline SPT & 3.46 & 3.64 & $4.18(* *)$ & $5.52(* *)$ \\
\hline STPT & 5.7 & 6.08 & $7.35(* *)$ & $8.27(* *)$ \\
\hline FCFS & 4.52 & 4.58 & 5.46 & $6.86(* *)$ \\
\hline FAFS & 6.72 & 7.15 & 7.57 & $8.92(* *)$ \\
\hline EDD & 1.28 & 1.13 & 1.45 & $2.35(* *)$ \\
\hline ODD & 0.69 & $0.68(*)$ & $1.10(* *)$ & $1.52(* *)$ \\
\hline MOD & 0.66 & 0.85 & $0.80(*)(* *)$ & $1.38(*)(* *)$ \\
\hline MDD & 1.3 & 1.18 & $1.68(* *)$ & $2.46(* *)$ \\
\hline
\end{tabular}

Table 4. Processing time variation simulation results for MT.

and FAFS. An interesting point to note is that the relative ranking of the rules does not change with increasing the PV\% level (figures 3 and 4).

In terms of the MT measure, MOD is the best rule at the tight due-dates regardless of the utilization and PV levels. We also note that with the loose due-dates, PV affects the relative performance of the rules. For example, at the high utilization/ loose due dates condition (table 4), EDD gives the best MT for PV $=0 \%$, but when the level of PV increases to $60 \%$, ODD displays better performance than EDD. Note that the difference in the performances of ODD and EDD is statistically significant (table 4). This shows that PV can create some cross-over effects on the rules for the MT measure. 
High Utilization (85\%) / Loose due-dates $(k=7)$

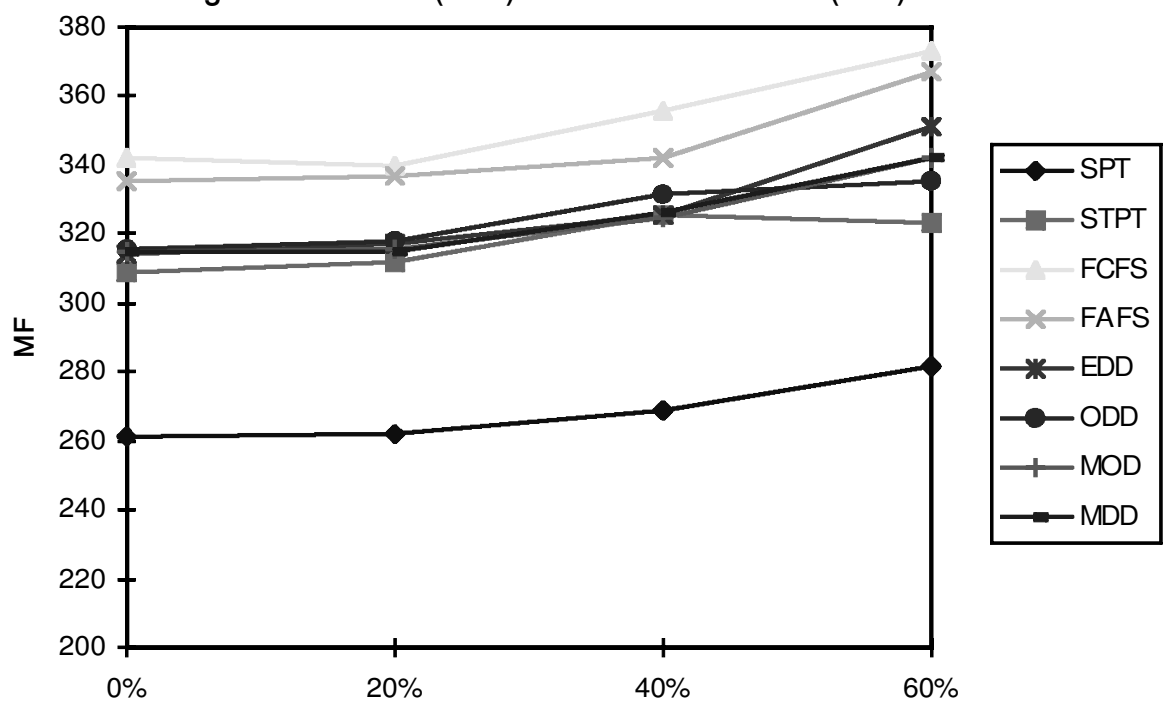

Processing Time variation Level \%

Figure 3. MF versus PV.

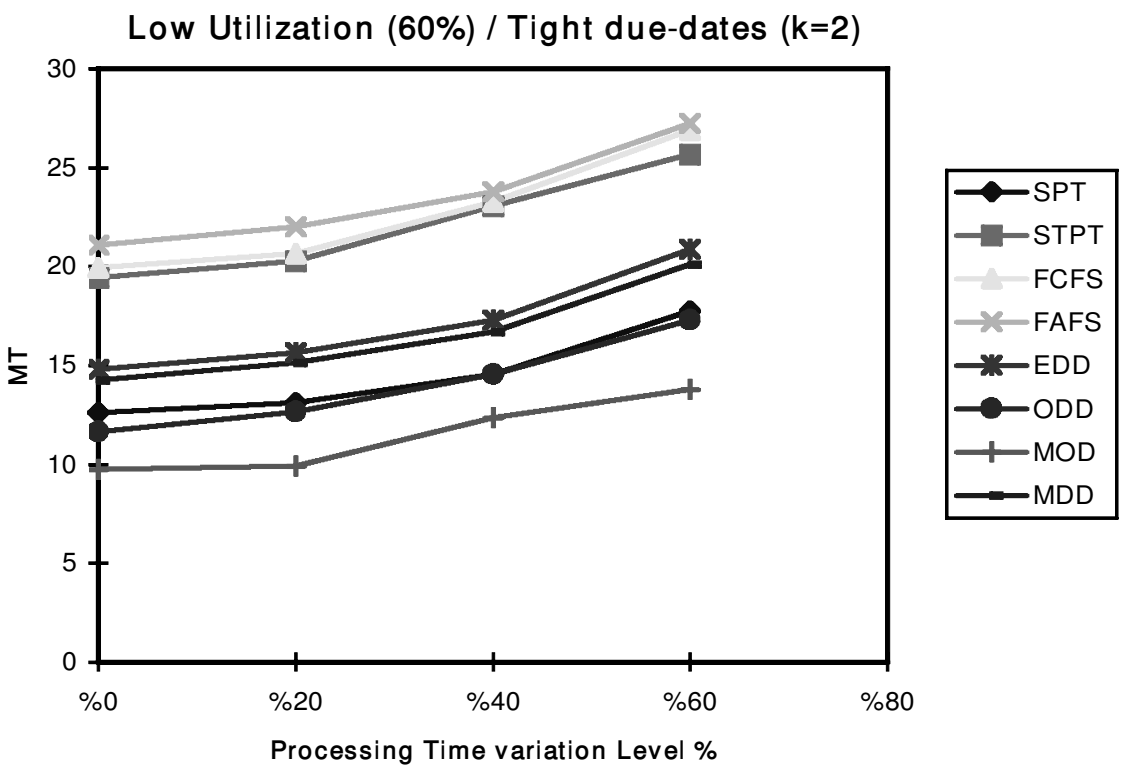

Figure 4. MT versus PV.

Another important point is that, up to the PV $=20 \%$ level, there is little effect on the MF or MT performance of the rules, whereas, beyond PV $=40 \%$, deterioration becomes more severe and the adverse effect of the increasing PV is observed (figure 4). Similar observations were also made by Yumin et al. (1994). In fact, this result came up with our previous expectation that PV has a negative effect on the system 


\begin{tabular}{|c|c|c|c|}
\hline & \multicolumn{3}{|c|}{ LV level \% } \\
\hline & $0 \%$ & $40 \%$ & $80 \%$ \\
\hline & \multicolumn{3}{|c|}{ Tight due-dates $(k=2.6)$} \\
\hline SPT & $186.52(*)$ & $190.12(*)$ & $194.16(*)(* *)$ \\
\hline STPT & 207.72 & $211.06(* *)$ & $214.58(* *)$ \\
\hline FCFS & 223.42 & 224.65 & $230.10(* *)$ \\
\hline FAFS & 218.63 & $222.41(* *)$ & $228.64(* *)$ \\
\hline EDD & 213.20 & $217.07(* *)$ & $221.46(* *)$ \\
\hline ODD & 205.55 & $210.10(* *)$ & $214.54(* *)$ \\
\hline MOD & 197.59 & 200.93 & $202.82(* *)$ \\
\hline MDD & 210.86 & 212.19 & $216.74(* *)$ \\
\hline \multicolumn{4}{|c|}{ Loose due-dates $(k=4.5)$} \\
\hline SPT & $186.52(*)$ & $190.12(*)$ & $194.16(*)(* *)$ \\
\hline STPT & 207.72 & $211.06(* *)$ & $214.58(* *)$ \\
\hline FCFS & 223.42 & 224.65 & $230.10(* *)$ \\
\hline FAFS & 218.63 & $222.41(* *)$ & $228.64(* *)$ \\
\hline EDD & 211.59 & 214.98 & $217.35(* *)$ \\
\hline ODD & 209.18 & $214.12(* *)$ & $216.88(* *)$ \\
\hline MOD & 208.31 & 212.95 & $215.37(* *)$ \\
\hline MDD & 211.16 & 214.77 & $217.74(* *)$ \\
\hline
\end{tabular}

Table 5. MF simulation results for Scheme 1.

\begin{tabular}{|c|c|c|c|}
\hline & \multicolumn{3}{|c|}{ LV level \% } \\
\hline & $0 \%$ & $40 \%$ & $80 \%$ \\
\hline & \multicolumn{3}{|c|}{ Tight due-dates $(k=2.6)$} \\
\hline SPT & $186.52(*)$ & $199.43(*)(* *)$ & $200.35(*)(* *)$ \\
\hline STPT & 207.72 & $222.66(* *)$ & $219.30(* *)$ \\
\hline FCFS & 223.42 & $244.22(* *)$ & $240.29(* *)$ \\
\hline FAFS & 218.63 & $238.43(* *)$ & $234.56(* *)$ \\
\hline EDD & 213.20 & $227.61(* *)$ & $226.40(* *)$ \\
\hline ODD & 205.55 & $224.09(* *)$ & $222.62(* *)$ \\
\hline MOD & 197.59 & $211.14(* *)$ & $208.57(* *)$ \\
\hline \multirow[t]{2}{*}{ MDD } & 210.86 & $220.66(* *)$ & $216.77(* *)$ \\
\hline & \multicolumn{3}{|c|}{ Loose due-dates $(k=4.5)$} \\
\hline SPT & $186.52(*)$ & $199.43(*)(* *)$ & $200.35(*)(* *)$ \\
\hline STPT & 207.72 & $222.66(* *)$ & $219.30(* *)$ \\
\hline FCFS & 223.42 & $244.22(* *)$ & $240.29(* *)$ \\
\hline FAFS & 218.63 & $238.43(* *)$ & $234.56(* *)$ \\
\hline EDD & 211.59 & $225.45(* *)$ & $219.57(* *)$ \\
\hline ODD & 209.18 & $227.30(* *)$ & $226.40(* *)$ \\
\hline MOD & 208.31 & $226.37(* *)$ & $223.72(* *)$ \\
\hline MDD & 211.16 & $226.42(* *)$ & $219.21(* *)$ \\
\hline
\end{tabular}

Table 6. MF simulation results for Scheme 2. 


\begin{tabular}{|c|c|c|c|}
\hline & No change & $\begin{array}{l}\text { Load variation } \\
\text { Strict. Increasing }\end{array}$ & Strict. Decreasing \\
\hline & \multicolumn{3}{|c|}{ Tight due-dates $(k=2.6)$} \\
\hline SPT & $186.52(*)$ & $181.62(*)$ & $196.68(*)$ \\
\hline STPT & 207.72 & 198.49 & 220.82 \\
\hline FCFS & 223.42 & 211.25 & 234.93 \\
\hline FAFS & 218.63 & 209.54 & 231.58 \\
\hline EDD & 213.20 & 203.30 & 223.26 \\
\hline ODD & 205.55 & 198.17 & 217.66 \\
\hline MOD & 197.59 & 190.70 & 204.80 \\
\hline \multirow[t]{2}{*}{ MDD } & 210.86 & 198.71 & 219.69 \\
\hline & \multicolumn{3}{|c|}{ Loose due-dates $(k=4.5)$} \\
\hline SPT & $186.52(*)$ & $181.62(*)$ & $196.68(*)$ \\
\hline STPT & 207.72 & 198.49 & 220.82 \\
\hline FCFS & 223.42 & 211.25 & 234.93 \\
\hline FAFS & 218.63 & 209.54 & 231.58 \\
\hline EDD & 211.59 & 200.52 & 221.31 \\
\hline ODD & 209.18 & 200.85 & 220.91 \\
\hline MOD & 208.31 & 200.55 & 219.51 \\
\hline MDD & 211.16 & 201.25 & 222.64 \\
\hline
\end{tabular}

Table 7. MF simulation results for Schemes 3 and 4.

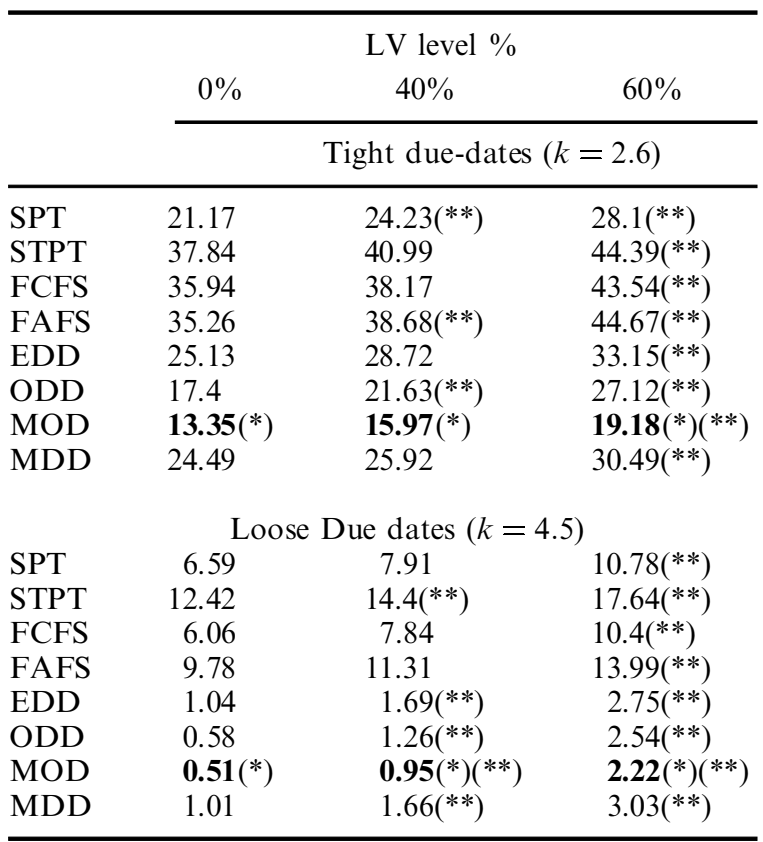

Table 8. MT simulation results for Scheme 1. 


\begin{tabular}{llcc}
\hline \multicolumn{4}{c}{ LV level \% } \\
& $0 \%$ & $40 \%$ & $60 \%$ \\
\cline { 2 - 4 } & \multicolumn{3}{c}{ Tight due-dates $(k=2.6)$} \\
\hline SPT & 21.17 & $33.26(* *)$ & $34.48(* *)$ \\
STPT & 37.84 & $52.57(* *)$ & $50.53(* *)$ \\
FCFS & 35.94 & $56.53(* *)$ & $55.08(* *)$ \\
FAFS & 35.26 & $53.79(* *)$ & $52.18(* *)$ \\
EDD & 25.13 & $40.25(* *)$ & $39.7(* *)$ \\
ODD & 17.4 & $35.39(* *)$ & $35.85(* *)$ \\
MOD & $\mathbf{1 3 . 3 5}(*)$ & $\mathbf{2 6 . 0 3}(*)(* *)$ & $\mathbf{2 5 . 2}(*)(* *)$ \\
MDD & 24.49 & $35.02(* *)$ & $33.44(* *)$ \\
& \multicolumn{3}{c}{ Loose due dates $(k=4.5)$} \\
SPT & 6.59 & $14.56(* *)$ & $14.58(* *)$ \\
STPT & 12.42 & $24.34(* *)$ & $22.05(* *)$ \\
FCFS & 6.06 & $15.7(* *)$ & $15.81(* *)$ \\
FAFS & 9.78 & $18.14(* *)$ & $18.02(* *)$ \\
EDD & 1.04 & $4.54(* *)$ & $3.71(* *)$ \\
ODD & 0.58 & $4.8(* *)$ & $5.19(* *)$ \\
MOD & $\mathbf{0 . 5 1}(*)$ & $4.98(* *)$ & $4.04(* *)$ \\
MDD & 1.01 & $\mathbf{4 . 2 2}(*)(* *)$ & $\mathbf{3 . 3 7}(*)(* *)$ \\
\hline
\end{tabular}

Table 9. MT simulation results for Scheme 2.

\begin{tabular}{|c|c|c|c|}
\hline & No change & $\begin{array}{l}\text { Load Variation } \\
\text { Strict. Increasing }\end{array}$ & Strict. Decreasing \\
\hline & \multicolumn{3}{|c|}{ Tight due-dates $(k=2.6)$} \\
\hline SPT & 21.17 & 19.51 & 28.77 \\
\hline STPT & 37.84 & 32.28 & 48.89 \\
\hline FCFS & 35.94 & 30.05 & 45.63 \\
\hline FAFS & 35.26 & 31.42 & 45.01 \\
\hline EDD & 25.13 & 20.96 & 33.65 \\
\hline ODD & 17.4 & 15.66 & 26.79 \\
\hline MOD & $13.35(*)$ & $11.77(*)$ & $18.74(*)$ \\
\hline \multirow[t]{2}{*}{ MDD } & 24.49 & 18.67 & 31.63 \\
\hline & \multicolumn{3}{|c|}{ Loose due dates $(k=4.5)$} \\
\hline SPT & 6.59 & 5.94 & 10.88 \\
\hline STPT & 12.42 & 10.59 & 20.45 \\
\hline FCFS & 6.06 & 5.19 & 10.11 \\
\hline FAFS & 9.78 & 8.69 & 13.63 \\
\hline EDD & 1.04 & 0.69 & 2.57 \\
\hline ODD & 0.58 & $0.38(*)$ & 2.51 \\
\hline MOD & $0.51(*)$ & 0.45 & $2.37(*)$ \\
\hline MDD & 1.01 & 0.6 & 2.57 \\
\hline
\end{tabular}

Table 10. MT simulation results for Schemes 3 and 4 . 
performance; however, we can provide no explicit explanation for such an effect. Interestingly, the simple rules are robust up to an intermediate level of PV, indicating that their use would still be applicable at least to a certain extent, within the presence of such variation.

\subsection{Results of load variation}

The results of the simulation runs are presented in tables 5-10. As in the PV case, the results are tested for statistical significance at the $95 \%$ confidence level. Figures 5-9 are also included to support the findings further.

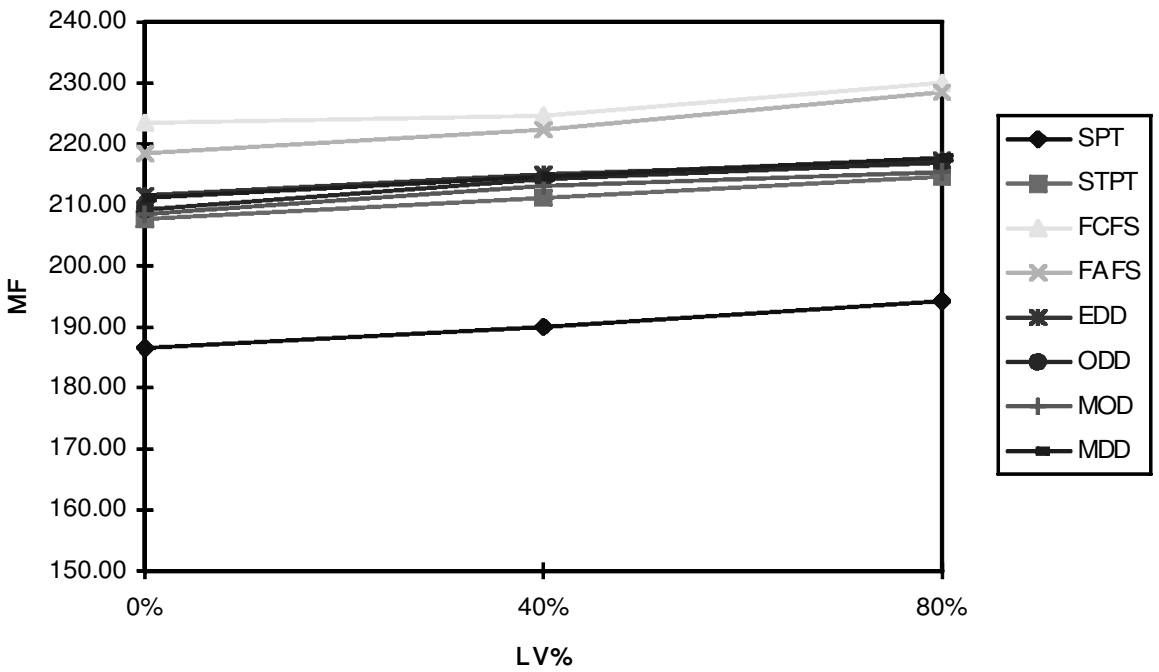

Figure 5. MF versus LV/Scheme $1 /$ loose due dates $(k=4.5)$.
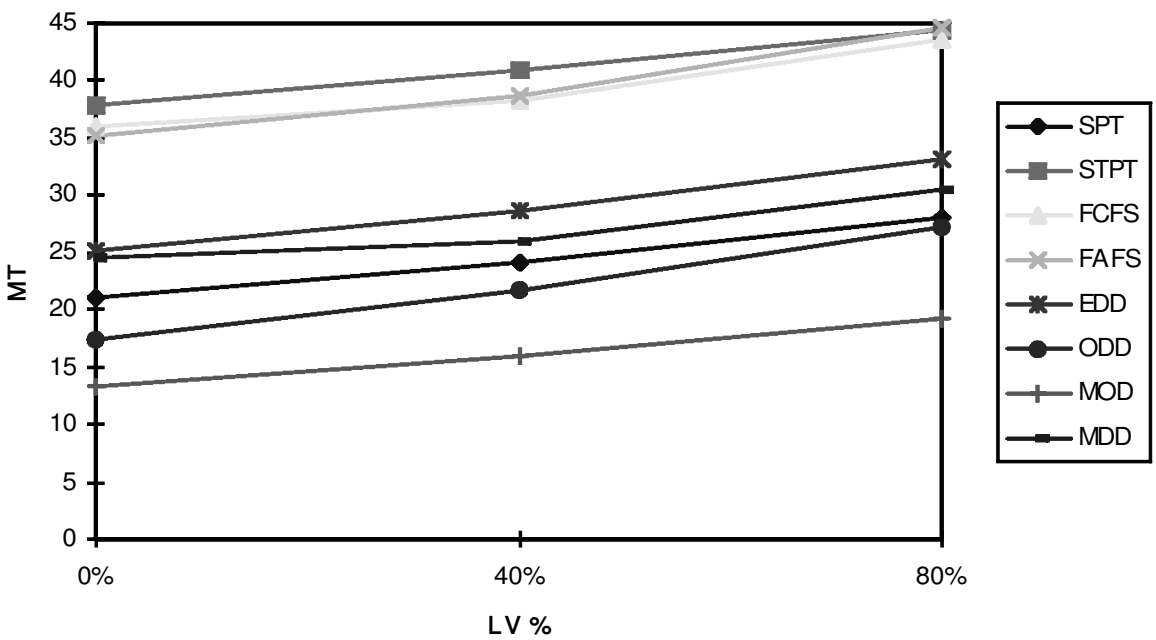

Figure 6. MT versus $\mathrm{LV} / \mathrm{Scheme} 1 /$ tight due dates $(k=2.6)$. 


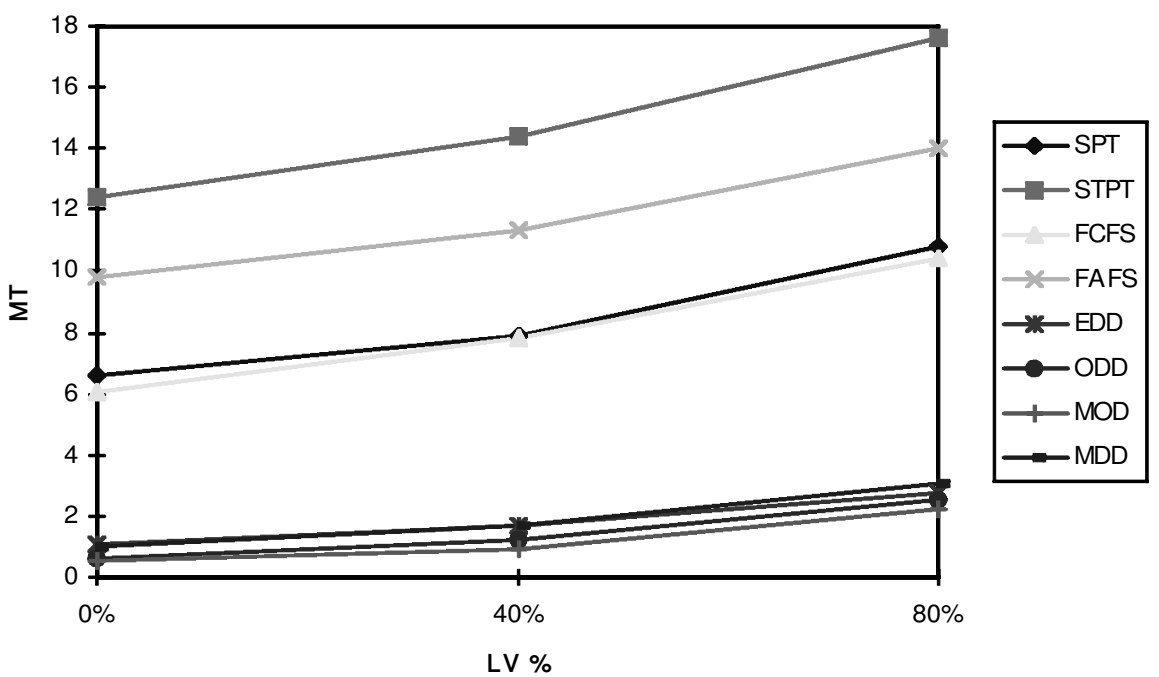

Figure 7. MT versus LV/Scheme $1 /$ Loose due dates $(k=4.5)$.

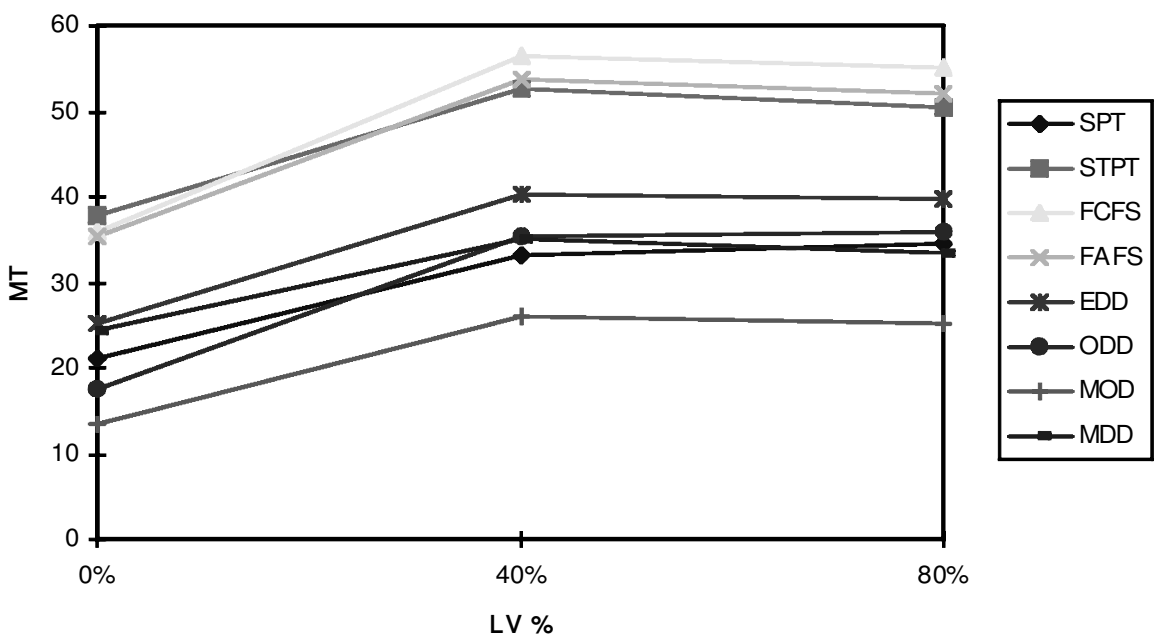

Figure 8. MT versus $\mathrm{LV} /$ Scheme $2 /$ tight due dates $(k=2.6)$.

We have the following observations. Similar to the PV case, SPT dominates all other rules for the MF measure. This indicates that, despite the presence of LV, the relative performance of SPT with other competing rules stays unaffected. The second best performance is shared by MOD with tight due dates and by STPT with loose due-dates. These two rules are followed by ODD, MDD, EDD, FAFS and FCFS. We note that the relative ranking of the rules remained the same with the LV. Among the rules, SPT seems to be the most robust rule to the changes in LV (figure 5).

In contrast, we observe crossovers between the rules when LV is seasonal (Scheme 2) or is increasing (Scheme 3). For instance, in the seasonal LV case: 


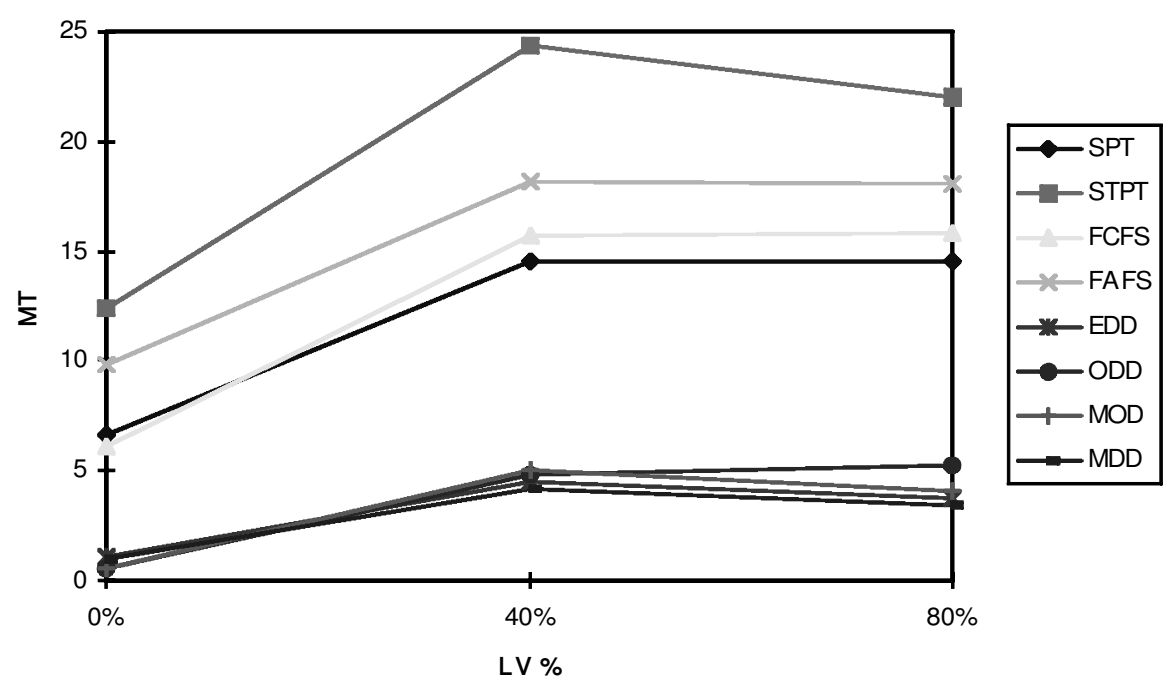

Figure 9. MT versus LV/Scheme 2/loose due dates $(k=4.5)$.

when $\mathrm{LV} \%=0 \%$, MOD gives the best MT performance for loose due-dates. However, beyond the $\mathrm{LV} \%=40 \%$, MDD performs significantly better than MOD and other rules. A similar crossover is observed between MOD and ODD when LV is increasing (Scheme 3). Nevertheless, apart from these exceptions, MOD yields the best MT performance.

In the case of random LV (Scheme 1), the MF and MT performances of the rules deteriorate beyond the $\mathrm{LV} \%=40 \%$ level. Importantly, This effect becomes more severe at the $80 \%$ level (figures 5-7). However, with seasonal LV (Scheme 2), even though the performance of the rules deteriorate at the $40 \%$ level, no further deterioration occurs at the $80 \%$ level (figures 8 and 9). This indicates that the performances of the rules are only sensitive to the seasonal pattern of LV change and not to the magnitude of the seasonal waves (figure 1(b)). Another interesting observation is that the performances deteriorate significantly with decreasing load level (scheme 4, tables 7 and 10), but slightly improve with increasing load level (scheme 3, tables 7 and 10). Our major conclusion is that LV negatively affects the MF and MT performance of scheduling rules. This conclusion contradicts the results of Sabuncuoglu and Comlekci (1997) that report the robustness of rules to LV, although the latter study was done in the context of flow time estimation. Nevertheless, it is crucial to note that the LV effect is due to a combination of two factors: pattern (presented by the different schemes) and magnitude (controlled by $\mathrm{LV} \%$ ). The LV pattern, random, seasonal, or increasing, can only have a negative effect. The LV magnitude, depending on the LV pattern has either neutral (seasonal) or negative (random) effect. In summary, LV has negative effects on the performances of the rules, and the degree of the impact depends on the LV pattern and magnitude.

\subsection{Results of due date variation}

The rules are tested under four levels of due date variation: $20 \%, 40 \%, 60 \%$ and $80 \%$. Two performance measures, MF and MT are used to avoid bias. To seek 
generality, two system load levels $60 \%$ and $85 \%$ as well as two due date tightness levels (Tight and Loose) are considered. In order to investigate the effect of increasing the probability $p$ of occurrence of due date changes, we consider two $p$ levels: 0.05 and 0.10 . The simulation results are illustrated in tables $11-16$. The paired $t$ tests are applied to compare the best rule with the next best rule at a significance level of $5 \%$. The symbol $(*)$ indicates that the difference is significant. In addition, the paired $t$-tests are also used to compare the original performance (i.e. with no due date variation) of a rule with its new performance when DV\% level is increased. The symbol (**) indicates that the difference is significant.

\subsubsection{Mean flowtime criterion}

Primarily, we should mention that non due-date based rules such as SPT, STPT, FCFS and FAFS rules are insensitive to the due date variation factor. This is due to

\begin{tabular}{|c|c|c|c|c|c|}
\hline & \multicolumn{5}{|c|}{ Due date variation $\%$} \\
\hline & $0 \%$ & $20 \%$ & $40 \%$ & $60 \%$ & $80 \%$ \\
\hline & \multicolumn{5}{|c|}{$\begin{array}{l}\text { High utilization }(85 \%) / \text { Tight due dates }(k=4.5) \\
\qquad p=0.05\end{array}$} \\
\hline SPT & $260.12 *$ & $260.12 *$ & $260.12 *$ & $260.12 *$ & $260.12 *$ \\
\hline STPT & 308.30 & 308.30 & 308.30 & 308.30 & 308.30 \\
\hline FCFS & 342.15 & 342.15 & 342.15 & 342.15 & 342.15 \\
\hline FAFS & 336.59 & 336.59 & 336.59 & 336.59 & 336.59 \\
\hline EDD & 319.67 & 320.99 & 322.88 & 314.17 & 316.58 \\
\hline ODD & 310.27 & 312.59 & 309.39 & 311.73 & 308.84 \\
\hline MOD & 300.15 & 301.87 & 304.38 & 303.85 & 299.46 \\
\hline MDD & 314.44 & 315.22 & 316.27 & 313.91 & 315.70 \\
\hline & & & $p=0.10$ & & \\
\hline EDD & 319.67 & 317.23 & 321.29 & 318.91 & 314.69 \\
\hline ODD & 310.27 & 310.64 & 310.64 & 314.27 & 315.50 \\
\hline MOD & 300.15 & 300.87 & 301.91 & 301.33 & 303.87 \\
\hline MDD & 314.44 & 317.11 & 319.20 & 312.24 & 319.39 \\
\hline
\end{tabular}

High utilization $(85 \%) /$ Loose due dates $(k=7)$

\begin{tabular}{llllll} 
& & & $p=0.05$ & \\
SPT & $\mathbf{2 6 0 . 1 2}$ & $\mathbf{2 6 0 . 1 2}$ & $\mathbf{2 6 0 . 1 2} *$ & $\mathbf{2 6 0 . 1 2 *}$ & $\mathbf{2 6 0 . 1 2 *}$ \\
STPT & 308.30 & 308.30 & 308.30 & 308.30 & 308.30 \\
FCFS & 342.15 & 342.15 & 342.15 & 342.15 & 342.15 \\
FAFS & 336.59 & 336.59 & 336.59 & 336.59 & 336.59 \\
EDD & 313.20 & 315.45 & 316.49 & 314.21 & 316.35 \\
ODD & 315.72 & 315.44 & 317.17 & 320.32 & 320.97 \\
MOD & 314.54 & 316.28 & 321.19 & 316.77 & 317.10 \\
MDD & 314.55 & 311.38 & 316.79 & 315.45 & 314.59 \\
& & & & & \\
EDD & 313.20 & 315.06 & 317.03 & 319.26 & 318.12 \\
ODD & 315.72 & 318.35 & 315.85 & 319.10 & 320.53 \\
MOD & 314.54 & 318.63 & 320.85 & 321.33 & 316.20 \\
MDD & 314.55 & 316.30 & 313.76 & 320.06 & 317.65 \\
\hline
\end{tabular}

Table 11. MF summary of results. 


\begin{tabular}{|c|c|c|c|c|c|}
\hline & \multicolumn{5}{|c|}{ Due date variation $\%$} \\
\hline & $0 \%$ & $20 \%$ & $40 \%$ & $60 \%$ & $80 \%$ \\
\hline & \multicolumn{5}{|c|}{$\begin{array}{l}\text { Low utilization }(60 \%) / \text { tight due dates }(k=2) \\
\qquad p=0.05\end{array}$} \\
\hline SPT & $149.36 *$ & $149.36 *$ & $149.36 *$ & $149.36 *$ & $149.36^{*}$ \\
\hline STPT & 159.31 & 159.31 & 159.31 & 159.31 & 159.31 \\
\hline FCFS & 165.09 & 165.09 & 165.09 & 165.09 & 165.09 \\
\hline FAFS & 163.53 & 163.53 & 163.53 & 163.53 & 163.53 \\
\hline EDD & 159.31 & 160.22 & 160.00 & 160.63 & 159.68 \\
\hline ODD & 157.61 & 158.00 & 158.20 & 157.91 & 158.37 \\
\hline MOD & 154.25 & 154.02 & 153.70 & 153.74 & 154.28 \\
\hline \multirow[t]{2}{*}{ MDD } & 158.40 & 159.03 & 159.28 & 159.38 & 158.26 \\
\hline & \multicolumn{5}{|c|}{$p=0.10$} \\
\hline EDD & 159.31 & 159.45 & 160.02 & 159.82 & 160.07 \\
\hline ODD & 157.61 & 158.19 & 159.03 & 159.23 & 158.20 \\
\hline MOD & 154.25 & 154.05 & 153.98 & 154.20 & 154.37 \\
\hline \multirow[t]{2}{*}{ MDD } & 158.40 & 159.13 & 159.18 & 160.51 & 160.02 \\
\hline & \multicolumn{5}{|c|}{$\begin{array}{l}\text { Low utilization }(60 \%) / \text { loose due dates }(k=3) \\
p=0.05\end{array}$} \\
\hline SPT & $149.36 *$ & $149.36 *$ & $149.36 *$ & $149.36 *$ & $149.36^{*}$ \\
\hline STPT & 159.31 & 159.31 & 159.31 & 159.31 & 159.31 \\
\hline FCFS & 165.09 & 165.09 & 165.09 & 165.09 & 165.09 \\
\hline FAFS & 163.53 & 163.53 & 163.53 & 163.53 & 163.53 \\
\hline EDD & 159.52 & 159.93 & 159.00 & 158.36 & 159.18 \\
\hline ODD & 158.92 & 158.32 & 159.06 & 159.53 & 158.77 \\
\hline MOD & 158.83 & 158.35 & 159.17 & 159.06 & 159.06 \\
\hline MDD & 158.96 & 160.14 & 158.82 & 159.54 & 159.24 \\
\hline & & & $p=0.10$ & & \\
\hline EDD & 159.52 & 160.55 & 160.04 & 159.86 & 160.31 \\
\hline ODD & 158.92 & 158.60 & 159.79 & 159.67 & 160.24 \\
\hline MOD & 158.83 & 158.41 & 158.94 & 158.91 & 158.60 \\
\hline MDD & 158.96 & 159.64 & 159.67 & 160.33 & 160.30 \\
\hline
\end{tabular}

Table 12. MF summary of results.

their primal nature that they do not consider any due date information. Consequently, as expected, these rules produce the same MF performances with all five due date variation levels. We also observe that SPT always gives best MF values despite the DDV (due date variation) level, in all experimental conditions (tables 11 and 12). This indicates that DDV does not affect the relative performance of SPT with other due-date based competing rules. Furthermore, we observe that regarding EDD, ODD, MOD and MDD, although due-date based rules, their performances are not affected considerably by DDV in the high utilization case. In the low utilization case, we notice that their performances do not undergo regular deterioration; instead, the performance of the rules fluctuates up and down. Nevertheless, the magnitude of up/down performance fluctuations is statistically insignificant (table 12). In summary, we conclude that the performances of priority rules are quite robust to DDV with respect to the MF measure. In addition, DDV 


\begin{tabular}{|c|c|c|c|c|c|}
\hline \multirow[b]{4}{*}{ SPT } & \multicolumn{5}{|c|}{ Due date variation $\%$} \\
\hline & $0 \%$ & $20 \%$ & $40 \%$ & $60 \%$ & $80 \%$ \\
\hline & \multicolumn{5}{|c|}{$\begin{array}{l}\text { High utilization }(85 \%) / \text { tight due dates }(k=4.5) \\
\qquad p=0.05\end{array}$} \\
\hline & 36.04 & 36.04 & 36.04 & 36.04 & 36.04 \\
\hline STPT & 72.76 & 72.76 & 72.76 & 72.76 & 72.76 \\
\hline FCFS & 45.94 & 45.94 & 45.94 & 45.94 & 45.94 \\
\hline FAFS & 49.37 & 49.37 & 49.37 & 49.37 & 49.37 \\
\hline EDD & 21.12 & 22.42 & 23.55 & 20.87 & 22.26 \\
\hline ODD & 17.15 & 18.29 & $19.30(* *)$ & $21.94(* *)$ & $22.91(* *)$ \\
\hline MOD & $13.06^{*}$ & $14.49 *$ & $16.74 *(* *)$ & $19.00 *(* *)$ & $19.88 *(* *)$ \\
\hline \multirow[t]{2}{*}{ MDD } & 18.38 & 19.86 & 19.63 & $20.77(* *)$ & $22.84(* *)$ \\
\hline & \multicolumn{5}{|c|}{$p=0.10$} \\
\hline EDD & 21.12 & 20.11 & 23.16 & $25.49(* *)$ & $24.69(* *)$ \\
\hline ODD & 17.15 & $19.08(* *)$ & $21.34(* *)$ & $28.09(* *)$ & $31.62(* *)$ \\
\hline MOD & $13.06 *$ & $15.08 *(* *)$ & $18.98 *(* *)$ & $23.13(* *)$ & $28.23(* *)$ \\
\hline \multirow[t]{2}{*}{ MDD } & 18.38 & 19.73 & $22.84(* *)$ & $22.98(* *)$ & $27.94(* *)$ \\
\hline & \multicolumn{5}{|c|}{$\begin{array}{l}\text { High utilization }(85 \%) / \text { loose due dates }(k=7) \\
p=0.05\end{array}$} \\
\hline SPT & 18.83 & 18.83 & 18.83 & 18.83 & 18.83 \\
\hline STPT & 40.09 & 40.09 & 40.09 & 40.09 & 40.09 \\
\hline FCFS & 11.38 & 11.38 & 11.38 & 11.38 & 11.38 \\
\hline FAFS & 20.06 & 20.06 & 20.06 & 20.06 & 20.06 \\
\hline EDD & $0.24 *$ & $0.47(* *)$ & $1.10(* *)$ & $2.24(* *)$ & $4.46(* *)$ \\
\hline ODD & 0.54 & $0.95(* *)$ & $2.56(* *)$ & $5.65(* *)$ & $8.58(* *)$ \\
\hline MOD & 0.51 & $1.08(* *)$ & $2.92(* *)$ & $5.90(* *)$ & $7.13(* *)$ \\
\hline MDD & 0.30 & $0.48(* *)$ & $1.08(* *)$ & $2.14(* *)$ & $3.75 *(* *)$ \\
\hline & & & $p=0.10$ & & \\
\hline EDD & $0.24 *$ & $0.59(* *)$ & $1.95(* *)$ & $4.82(* *)$ & $7.36 *(* *)$ \\
\hline ODD & 0.54 & $1.68(* *)$ & $4.87(* *)$ & $9.75(* *)$ & $13.84(* *)$ \\
\hline MOD & 0.51 & $1.49(* *)$ & $4.82(* *)$ & $10.29(* *)$ & $12.39(* *)$ \\
\hline MDD & 0.30 & $0.54(* *)$ & $1.77 *(* *)$ & $4.59 *(* *)$ & $8.40(* *)$ \\
\hline
\end{tabular}

Table 13. Type I effect/MT summary of results.

does not have any significant impact on the relative performance. In particular, SPT is always the best performing rule despite any DDV level.

\subsubsection{Mean tardiness criterion}

Analysis of due date variation for Type-I effect. The simulation results are tabulated in tables 13 and 14. As expected, non due-date based rules are insensitive to the Type-I effect since these rules do not consider any due date information. On the other hand, due-date based rules undergo an increasing deterioration pattern along the four DDV levels. This suggests that the due date variation Type-I effect can have a negative impact on the MT performance of the rules. As a matter of fact, the degree of this impact varies from one experimental condition to another. We observe that the slope of the deterioration curves is higher in the high machine utilization case than in the low machine utilization case. Furthermore, if we compare the rules performances in the $p=0.05$ case with the $p=0.10$ case, we observe that the deterio- 


\begin{tabular}{|c|c|c|c|c|c|}
\hline \multirow[b]{4}{*}{ SPT } & \multicolumn{5}{|c|}{ Due date variation $\%$} \\
\hline & $0 \%$ & $20 \%$ & $40 \%$ & $60 \%$ & $80 \%$ \\
\hline & \multicolumn{5}{|c|}{$\begin{array}{l}\text { Low utilization }(60 \%) / \text { tight due dates }(k=2) \\
\qquad p=0.05\end{array}$} \\
\hline & 12.60 & 12.60 & 12.60 & 12.60 & 12.60 \\
\hline STPT & 19.24 & 19.24 & 19.24 & 19.24 & 19.24 \\
\hline FCFS & 19.91 & 19.91 & 19.91 & 19.91 & 19.91 \\
\hline FAFS & 21.23 & 21.23 & 21.23 & 21.23 & 21.23 \\
\hline EDD & 14.78 & 15.26 & 14.95 & 15.61 & 15.15 \\
\hline ODD & 11.62 & 12.06 & 12.45 & 12.58 & $13.16(* *)$ \\
\hline MOD & $9.74 *$ & $10.12 *$ & $10.18 *$ & $10.43 *$ & $10.77^{*}$ \\
\hline \multirow[t]{2}{*}{ MDD } & 14.28 & 14.97 & 15.22 & 15.48 & 14.85 \\
\hline & \multicolumn{5}{|c|}{$p=0.10$} \\
\hline EDD & 14.78 & 14.87 & 15.52 & 15.34 & 15.76 \\
\hline ODD & 11.62 & 12.32 & 13.26 & 13.80 & $13.86(* *)$ \\
\hline MOD & $9.74 *$ & $10.09 *$ & $10.37 *$ & $11.02 *$ & $11.55^{*}$ \\
\hline \multirow[t]{2}{*}{ MDD } & 14.28 & 14.94 & 15.02 & 16.13 & $16.24(* *)$ \\
\hline & \multicolumn{5}{|c|}{$\begin{array}{l}\text { Low utilization }(60 \%) / \text { loose due dates }(k=3) \\
p=0.05\end{array}$} \\
\hline SPT & 3.48 & 3.48 & 3.48 & 3.48 & 3.48 \\
\hline STPT & 5.55 & 5.55 & 5.55 & 5.55 & 5.55 \\
\hline FCFS & 4.43 & 4.43 & 4.43 & 4.43 & 4.43 \\
\hline FAFS & 6.84 & 6.84 & 6.84 & 6.84 & 6.84 \\
\hline EDD & 1.26 & $1.36(* *)$ & $1.36(* *)$ & $1.41(* *)$ & $1.69(* *)$ \\
\hline ODD & 0.69 & $0.82(* *)$ & $1.13(* *)$ & $1.42(* *)$ & $1.79(* *)$ \\
\hline MOD & 0.66 & $0.70 *$ & $1.11(* *)$ & $1.41(* *)$ & $1.62(* *)$ \\
\hline MDD & 1.24 & $1.43(* *)$ & 1.20 & $1.43(* *)$ & $1.71(* *)$ \\
\hline & & & $p=0.10$ & & \\
\hline EDD & 1.26 & $1.42(* *)$ & $1.50(* *)$ & $2.00(* *)$ & $2.26(* *)$ \\
\hline ODD & 0.69 & $0.91(* *)$ & $1.53(* *)$ & $1.89(* *)$ & $2.89(* *)$ \\
\hline MOD & 0.66 & $0.86(* *)$ & $1.34 *(* *)$ & $1.87(* *)$ & $2.22(* *)$ \\
\hline MDD & 1.24 & $1.47(* *)$ & $1.63(* *)$ & $2.09(* *)$ & $2.19(* *)$ \\
\hline
\end{tabular}

Table 14. Type I effect/MT summary of results (continued).

ration patterns become more severe for almost all due-date based rules. This indicates that the DDV Type-I effect has a more negative impact on the performance of the rules as either the probability at which due date changes occur or the machine utilization level is increased.

Furthermore, from tables 13 and 14, we analyse the following behaviour of some rules; global rules such as MDD and EDD are more robust to Type-I effects than local rules like ODD and MOD. This is deduced by comparing the rates at which the rules performance is deteriorated as the DDV level is increased. For instance, according to table 13, we measure the magnitude of the MT performance deterioration from the $\mathrm{DV}=0 \%$ to the $\mathrm{DV}=80 \%$ level. We find out that the performances of ODD and MOD's performances worsen 30\% in magnitude, whereas EDD and MDD's performances worsen by only about $10 \%$ in magnitude. This suggests that a rule which utilizes global information (i.e. job due dates) instead of local 


\begin{tabular}{|c|c|c|c|c|c|}
\hline & \multicolumn{5}{|c|}{ Due data variation $\%$} \\
\hline & $0 \%$ & $20 \%$ & $40 \%$ & $60 \%$ & $80 \%$ \\
\hline & \multicolumn{5}{|c|}{$\begin{array}{l}\text { High utilization }(85 \%) / \text { Tight due dates }(k=4.5) \\
\qquad p=0.05\end{array}$} \\
\hline SPT & 36.04 & 33.07 & 33.55 & 34.48 & 36.28 \\
\hline STPT & 72.76 & 63.11 & 63.53 & 64.49 & 66.35 \\
\hline FCFS & 45.94 & 44.05 & 45.18 & 47.18 & 50.07 \\
\hline FAFS & 49.37 & 45.69 & 46.11 & 46.96 & 48.51 \\
\hline EDD & 21.12 & 18.27 & 18.44 & 15.68 & 15.58 \\
\hline ODD & 17.15 & 16.86 & 15.88 & 16.90 & 16.24 \\
\hline MOD & $13.06 *$ & $12.46 *$ & $13.08 *$ & $12.73 *$ & $11.80 *$ \\
\hline MDD & 18.38 & 15.38 & 14.63 & 14.62 & 14.69 \\
\hline $\begin{array}{l}\text { SPT } \\
\text { STPT } \\
\text { FCFS } \\
\text { FAFS } \\
\text { EDD } \\
\text { ODD } \\
\text { MOD } \\
\text { MDD }\end{array}$ & $\begin{array}{l}36.04 \\
72.76 \\
45.94 \\
49.37 \\
21.12 \\
17.15 \\
13.06 * \\
18.38\end{array}$ & $\begin{array}{l}28.79 \\
53.79 \\
42.35 \\
42.00 \\
13.32 \\
16.19 \\
11.43^{*} \\
12.22\end{array}$ & $\begin{array}{l}p=0.10 \\
29.60 \\
54.38 \\
44.55 \\
42.51 \\
14.48 \\
15.83 \\
11.61 * \\
12.38\end{array}$ & $\begin{array}{l}31.15 \\
55.82 \\
48.16 \\
43.79 \\
14.52 \\
18.14 \\
11.73 \\
\mathbf{1 1 . 2 1}\end{array}$ & $\begin{array}{l}34.15 \\
58.65 \\
52.98(* *) \\
46.14 \\
13.34 \\
18.48\left(^{* *}\right) \\
\mathbf{1 2 . 1 0 *} \\
13.11\end{array}$ \\
\hline MDD & \multicolumn{5}{|c|}{$\begin{array}{l}\text { High utilization }(85 \%) / \text { Loose due dates }(k=7) \\
\qquad p=0.05\end{array}$} \\
\hline SPT & 18.83 & 17.45 & 17.90 & 18.77 & 20.64 \\
\hline STPT & 40.09 & 35.29 & 35.98 & 37.29 & 39.75 \\
\hline FCFS & 11.38 & 11.43 & 12.44 & $14.75(* *)$ & $19.05(* *)$ \\
\hline FAFS & 20.06 & 19.22 & 19.50 & 20.18 & 21.86 \\
\hline EDD & $0.24^{*}$ & $0.32(* *)$ & $0.40(* *)$ & $0.40(* *)$ & $0.56(* *)$ \\
\hline ODD & 0.54 & 0.56 & 0.55 & 0.55 & $0.74(* *)$ \\
\hline MOD & 0.51 & 0.55 & 0.63 & 0.28 & $0.92(* *)$ \\
\hline MDD & 0.30 & 0.28 & $0.34^{*}$ & $0.23 *$ & $0.47 *(* *)$ \\
\hline & & & $p=0.10$ & & \\
\hline $\begin{array}{l}\text { SPI } \\
\text { STPT }\end{array}$ & $\begin{array}{l}18.83 \\
40.09\end{array}$ & $\begin{array}{l}15.03 \\
30.49\end{array}$ & $\begin{array}{l}15.60 \\
31.18\end{array}$ & $\begin{array}{l}17.05 \\
32.79\end{array}$ & $\begin{array}{l}20.12 \\
36.29\end{array}$ \\
\hline FCFS & 11.38 & 11.33 & 13.33 & $17.62(* *)$ & $25.16(* *)$ \\
\hline FAFS & 20.06 & 18.46 & 18.89 & 20.04 & 22.77 \\
\hline EDD & $0.24 *$ & $0.24 *$ & $0.27^{*}$ & 0.23 & $0.74(* *)$ \\
\hline ODD & 0.54 & $0.69(* *)$ & $0.66(* *)$ & $0.67(* *)$ & $1.10(* *)$ \\
\hline MOD & 0.51 & 0.47 & 0.64 & $0.73(* *)$ & $0.91(* *)$ \\
\hline MDD & 0.30 & 0.28 & 0.32 & 0.24 & $0.65 *(* *)$ \\
\hline
\end{tabular}

Table 15. DV overall effect/MT summary of results.

information (i.e. operation due dates) is more robust to the disturbances caused by the variation in due dates.

Based on the results obtained in this section, we present a summary table (table 17) which characterizes the effect of DDV on the priority rules for each experimental condition.

Analysis of due date variation overall effect. The results of the simulation runs are tabulated in tables 15 and 16. After analysing the results, we make the following observations. 


\begin{tabular}{|c|c|c|c|c|c|}
\hline & \multicolumn{5}{|c|}{ Due date variation $\%$} \\
\hline & $0 \%$ & $20 \%$ & $40 \%$ & $60 \%$ & $80 \%$ \\
\hline & \multicolumn{5}{|c|}{$\begin{array}{c}\text { Low utilization }(60 \%) / \text { Tight due dates }(k=2) \\
p=0.05\end{array}$} \\
\hline SPT & 12.60 & 11.52 & 11.75 & 12.18 & 12.90 \\
\hline STPT & 19.24 & 16.31 & 16.51 & 16.95 & 17.57 \\
\hline FCFS & 19.91 & 18.70 & 18.98 & 19.49 & 20.20 \\
\hline FAFS & 21.23 & 19.01 & 19.08 & 19.32 & 19.78 \\
\hline EDD & 14.78 & 13.18 & 12.53 & 13.08 & 13.06 \\
\hline ODD & 11.62 & 11.30 & 11.56 & 11.75 & 12.08 \\
\hline MOD & $9.74 *$ & $9.32 *$ & $9.16 *$ & $9.50 *$ & $9.97 *$ \\
\hline \multirow[t]{2}{*}{ MDD } & 14.28 & 12.27 & 12.54 & 12.87 & 12.07 \\
\hline & \multicolumn{5}{|c|}{$p=0.10$} \\
\hline SPT & 12.60 & 10.54 & 10.91 & 11.57 & 12.58 \\
\hline STPT & 19.24 & 14.57 & 14.89 & 15.57 & 16.59 \\
\hline FCFS & 19.91 & 17.88 & 18.34 & 19.15 & 20.22 \\
\hline FAFS & 21.23 & 17.39 & 17.54 & 17.95 & 18.71 \\
\hline EDD & 14.78 & 11.00 & 11.02 & 10.70 & 11.39 \\
\hline ODD & 11.62 & 10.84 & 11.40 & 11.92 & 12.29 \\
\hline MOD & 9.74* & $8.66^{*}$ & 8.58* & $9.17 *$ & 10.06 \\
\hline \multirow[t]{3}{*}{ MDD } & 14.28 & 10.20 & 10.39 & 11.15 & 11.20 \\
\hline & \multirow{2}{*}{\multicolumn{5}{|c|}{$\begin{array}{c}\text { Low utilization }(60 \%) / \text { Loose due dates }(k=3) \\
p=0.05\end{array}$}} \\
\hline & & & & & \\
\hline $\begin{array}{l}\text { SP 1 } \\
\text { STPT }\end{array}$ & $\begin{array}{l}5.40 \\
5.55\end{array}$ & $\begin{array}{l}3.19 \\
4.77\end{array}$ & $\begin{array}{l}3.31 \\
5.02\end{array}$ & 3.64 & $4.5 /(* *)$ \\
\hline FCFS & 4.43 & 4.27 & $\begin{array}{l}5.02 \\
4.58\end{array}$ & $\begin{array}{l}5.01 \\
5.24(* *)\end{array}$ & $6.57(* *)$ \\
\hline FAFS & 6.84 & 6.49 & 6.57 & 6.83 & 7.51 \\
\hline EDD & 1.26 & 1.16 & 1.06 & 1.05 & $1.56(* *)$ \\
\hline ODD & 0.69 & 0.74 & 0.76 & $0.96(* *)$ & $1.24(* *)$ \\
\hline MOD & 0.66 & $0.58 *$ & 0.71 & $0.74 *$ & $1.16 *(* *)$ \\
\hline \multirow[t]{2}{*}{ MDD } & 1.24 & 1.16 & 1.02 & 1.12 & $1.76(* *)$ \\
\hline & & & $p=0.10$ & & \\
\hline SPT & 3.48 & 2.91 & 3.19 & 3.90 & $5.39(* *)$ \\
\hline STPT & 5.55 & 4.43 & 4.92 & 5.94 & $7.84(* *)$ \\
\hline FCFS & 4.43 & 4.25 & 4.81 & $6.02(* *)$ & $8.18(* *)$ \\
\hline FAFS & 6.84 & 6.21 & 6.36 & 6.84 & $8.07(* *)$ \\
\hline EDD & 1.26 & 1.00 & 0.99 & 1.35 & $1.98(* *)$ \\
\hline ODD & 0.69 & 0.71 & $0.83(* *)$ & $0.99(* *)$ & $1.99(* *)$ \\
\hline MOD & 0.66 & $0.57 *$ & $0.67 *$ & $0.91(* *)$ & $1.83 *(* *)$ \\
\hline MDD & 1.24 & 1.01 & $0.99(* *)$ & $1.18(* *)$ & $2.02(* *)$ \\
\hline
\end{tabular}

Table 16. DV Overall effect/MT summary of results.

The performances of due-date based rules, although they improve at the DV $=20 \%$ level, undergo almost no change as DDV increases beyond the $40 \%$ level. This indicates that due-date based rules are quite robust to the overall effect of DDV. Note that MOD displays the best MT performance in almost all experimental conditions. Even though the probability of DDV occurrence $p$ is increased from 0.05 to 0.10 , we observe no changes; due-date based rules are still unaffected by DDV. In general, the relative performance of the priority rules is unaffected by 


\begin{tabular}{|c|c|c|c|}
\hline & \multirow[b]{2}{*}{ Best rule } & \multicolumn{2}{|c|}{ MT Performance Deterioration State } \\
\hline & & Low prob. $(p=0.05)$ & High prob. $(p=0.10)$ \\
\hline $\begin{array}{l}\text { High utilization / } \\
\text { tight due dates } \\
\text { case }\end{array}$ & MOD & $\begin{array}{l}\text { Moderate for local rules, } \\
\text { MOD and ODD. } \\
\text { Less severe for global } \\
\text { rules, EDD and MDD. }\end{array}$ & Becomes more severe \\
\hline $\begin{array}{l}\text { High utilization / } \\
\text { loose due dates } \\
\text { case }\end{array}$ & EDD & $\begin{array}{l}\text { Moderate for MOD and } \\
\text { ODD. } \\
\text { Less severe for EDD and } \\
\text { MDD. }\end{array}$ & Becomes more severe \\
\hline $\begin{array}{l}\text { Low utilization / } \\
\text { tight due dates } \\
\text { case }\end{array}$ & MOD & $\begin{array}{l}\text { Slightly observable } \\
\text { for MOD and ODD. } \\
\text { Almost unobservable } \\
\text { for EDD and MDD. }\end{array}$ & $\begin{array}{l}\text { Very insignificant } \\
\text { changes }\end{array}$ \\
\hline $\begin{array}{l}\text { Low utilization / } \\
\text { loose due dates } \\
\text { case }\end{array}$ & MOD & $\begin{array}{l}\text { Moderate for MOD and } \\
\text { ODD. } \\
\text { Less severe for EDD and } \\
\text { MDD. }\end{array}$ & Becomes more severe \\
\hline
\end{tabular}

Table 17. Type-I effect/summary of results.

DDV. Nevertheless, there are some exceptions. In the high utilization/loose due dates case, we observe a crossover between EDD and MDD (table 15). At the $\mathrm{DV}=0 \%$ level, EDD displays best MT performance; however, as we get beyond the $40 \%$ level, MDD displays the best MT values and outperforms EDD. Note that the differences between the performances of the two rules are statistically significant.

\section{Conclusions}

In this paper, we studied the performance of well-known dispatching rules under processing time and load variations against the MF and MT measures. The main findings of this study are as follows.

- Scheduling rules are not totally robust to PV. Their performances are adversely affected by PV, especially at high PV levels (above 40\%). This is consistent with the results of Sabuncuoglu and Comlekci (1997) who investigate the problem in the context of flow time estimation, but in their study, only two rules are used in the simulation experiments. In our study, however, we fully focus on this issue and analyse it by using eight well-known dispatching rules. In addition, the analysis is done under various experimental conditions. Hence, our results are more conclusive. Our results do not contradict the results of Sabuncuoglu and Karabuk (1999). The former study is carried out in a static environment for a finite planing horizon with the emphasis on the comparisons of optimum-seeking algorithms and simple scheduling rules. The authors have found that rules are more robust to variations and random interruptions. Here, in our study, we measure the robustness of the rules in a dynamic environment for a long planning horizon (i.e. long term behaviour). 
- The relative ranking of the rules is only slightly affected by PV but, in terms of MT, there are some exceptions noted for the ODD and EDD rules.

- LV, depending on its pattern and magnitude, has different but (at high variation) negative impacts on the performances of the scheduling rules for both the MF and MT measures. However, the relative performance of scheduling rules is unaffected by LV, with some exceptions for MOD, MDD and ODD in the case of the MT measure.

- The DDV Type-I effect, defined as the DDV effect due to changes in job completion times, negatively affects the performance of due-date based priority rules. The degree of this effect increases with the increasing probability that due dates change or as the machine utilization level increases.

- Global rules such as EDD and MDD are more robust to the DDV Type-I effect than local rules such as ODD and MOD.

- The MT performance of due-date based rules, although negatively affected by the Type-I effect, is quite robust to the overall effect of DDV. This indicates that the effect of DDV due to changes in completion times (Type-I effect), is eventually neutralized by the DDV effect due to changes in due dates (Type-II effect).

- The relative performances of priority rules are, in general, unaffected by the overall effect of DDV. However, there are still some exceptions that we noted for the rules EDD and MDD.

- In almost all experimental conditions, MOD gives the best MT values irrespective of the level of DDV. This confirms the results of previous studies for job shops. Furthermore, this makes us more confident in suggesting MOD as an effective rule for MT, even in job shop environments where variation in due dates can occur.

In conclusion, PV, LV and DDV do not much threaten the relative performance of the competing rules, even though they have an intense negative effect on their individual performances at high variation levels. Although the robustness of the relative performance of the rules to $\mathrm{PV} / \mathrm{LV} / \mathrm{DDV}$ provides a worthy relief to practitioners in the field, we suggest that PV/LV/DDV should not be ignored in the scheduling studies, barring that they may cause irreparable deficiencies to the whole job shop system performance. There is a need to develop new rules or scheduling mechanisms that are quite robust to variations in real production environments.

\section{References}

BAKER, K. R., 1984, Sequencing rules and due date assignments in a job shop. Management Science, 30(9), 1093-1104.

BAKer, C. T. and Dzielinski, B. P., 1960, Simulation of a simplified job shop. Management Science, 6(3), 311-323.

Carroll, D. C., 1965, Heuristic sequencing of single and multiple component jobs. PhD dissertation, MIT.

Conway, R. W., 1964, An experimental investigation of priority assignment in job shop. RAND Corp. Memo. RM-3789-PR (February).

Eilon, S. and Chowdhury, I. G., 1976, Due dates for job shop scheduling. International Journal of Production Research, 14, 223-237.

Elvers, D. A. and Taube, L. R., 1983, Time completion of various dispatching rules in job shops. Omega, 11(1), 81-89. 
Elvers, D. A., 1973, Job shop scheduling rules using various delivery due date setting criteria. Prod. Inv. Mgmt, 14(4), 62-70.

Frostig, E., 1988, A stochastic scheduling problem with intree precedence constraints. Operations Research, 36(6), 937-943.

Hottenstein, M. P., 1970, Expediting in job-order-control systems: a simulation study. AIIE Transactions, 6, 302.

Jones, C. H., 1973, An economic evaluation of job shop dispatching rules: a clarifying analysis. Management Science, 28(11), 1337-1341.

Law, A. M. and Kelton, W. D., 1991, Simulation Modeling and Analysis (McGraw-Hill).

Lawrence, S. R. and Sewell, E. C., 1997, Heuristic, optimal, static, and dynamic schedules when processing times are uncertain. Journal of Operations Management, 15, 71-82.

Pegden, C. D., Shannon, R. E. and Sadowsky, R. P., 1995, Introduction to Simulation Using Siman (McGraw-Hill).

Pinedo, M., 1982, Minimizing the expected makespan in stochastic flow shops. Operations Research, 30(1), 148-162.

Pinedo, M., 1995, Scheduling: Theory, Algorithms and Systems (Prentice-Hall).

Pinedo, M. and Weiss, G., 1987, The 'largest variance first' policy in some stochastic scheduling problems. Operations Research, 35(6), 884-891.

Ramasesh, R., 1990, Dynamic job shop scheduling: a survey of simulation research. International Journal of Management Science, 18(1), 43-57.

Sabuncuoglu, I. and Comlekci, A., 1997, Flowtime estimation in dynamic job shops. Research Report: IEOR-9714, Department of Industrial Engineering, Bilkent University.

Sabuncuoglu, I. and Karabuk, S., 1999, Rescheduling frequency in an FMS with uncertain processing times and unreliable machines. Journal of Manufacturing Systems, 18(4), 116.

Smith, M. L., Panwalker, S. S. and Dudek, R. A., 1973, Scheduling with uncertain processing times. 44th ORSA Meeting, San Diego, CA.

Suresh, S., Foley, R. D. and Dickey, S. E., 1985, On Pinedo's conjecture for scheduling in a stochastic flow shop. Operations Research, 33(5), 1146-1153.

Vepsalainen, A. P. J. and Morton, T. E., 1987, Priority rules for job shops with weighted tardiness costs. Management Science, 33(8), 1035-1047.

WeEks, J. K. and Fr Yer, J. S., 1977, A methodology for assigning minimum cost due dates. Management Science, 23(8), 872-881.

Yumin, H., Smith, M. L. and DudeK, R. A., 1994, Effects of inaccuracy of processing time estimation on effectiveness of dispatching rules. Institute of Industrial Engineers, 3rd Industrial Engineering Research Conference Proceedings. Hyatt Regency Atlanta, Atlanta, Georgia, 18-19 May. 